Revista Geográfica Digital. IGUNNE. Facultad de Humanidades. UNNE. Año 11. № 21.

Enero - Junio 2014. ISSN 1668-5180. Resistencia, Chaco.

\title{
LA OCURRENCIA DE HELADAS Y SU INFLUENCIA EN LAS FASES DE LOS CULTIVOS EN LA PROVINCIA DEL CHACO ENTRE 1951 Y 2000
}

\section{THE OCCURRENCE OF FROST AND ITS INFLUENCE ON THE STAGES OF CROPS IN THE PROVINCE OF CHACO BETWEEN 1951 AND 2000}

Prof. María de los Ángeles Martínez Jiménez

Becaria de la Secretaría General de Ciencia y Técnica.

Instituto de Geografía. Facultad de Humanidades. Universidad Nacional del Nordeste

Prof. Patricia Perla Snaider

Profesora Adjunta. Cátedra Climatología.

Departamento e Instituto de Geografía. Facultad de Humanidades. Universidad Nacional del Nordeste

\section{RESUMEN}

Los principales cultivos que se producen en nuestra región pueden verse afectados por la ocurrencia de eventos meteorológicos adversos que atentan contra su rendimiento.

En la provincia del Chaco, tanto la ocurrencia de heladas como su distribución espacial es variable, y esa falta de regularidad da al fenómeno un carácter de riesgo para ciertas prácticas agrícolas. Es por ello que, en una región que tiene como base de su economía a la actividad agrícola, el interés por conocer, analizar y mantener actualizados los estudios sobre este hidrometeoro está más que justificado.

Entonces, es fundamental estimar, tanto los períodos de ocurrencia de estos eventos, como el área en la que se producen, es decir, conocer el comportamiento y la influencia de las heladas en el Chaco durante los últimos 50 años, mediante el análisis estadístico y cartográfico, sumando a ello el apoyo bibliográfico.

De dicho análisis se deduce que las heladas invernales son las más intensas y frecuentes. Sin embargo, las heladas que con mayor frecuencia generan daños severos, son las heladas tempranas y tardías, es decir, las que ocurren en otoño y primavera respectivamente, aunque éstas sean de menor intensidad que las invernales. Asimismo, los daños que se generen en los cultivos dependerán de la sensibilidad y/o resistencia de los mismos ante las bajas temperaturas y de la fase del ciclo vital en la que se encuentren cada uno.

\section{PALABRAS CLAVES}

Frecuencia y duración de heladas; productividad agrícola; Chaco

\section{ABSTRACT}

The main crops produced in our region may be affected by the occurrence of adverse weather events that threaten your performance.

In the province of Chaco, both frosts and their spatial distribution is variable, and this lack of regularity gives the phenomenon a character risk for certain agricultural practices. That is why, in a region whose economy based on agricultural activity, interest in learning, analyzing and updating the hydrometeorological studies on this is more than justified.

It is essential then, to estimate both the periods of occurrence of these events, as the area in which they occur, ie, knowing the behavior and influence of frost in the Chaco for the past 50 years, through statistical analysis and cartographic, adding to it the bibliographic support.

Publicado en formato digital: Prof. María de los Ángeles Martínez Jiménez y Prof. Patricia Perla Snaider. LA OCURRENCIA DE HELADAS Y SU INFLUENCIA EN LAS FASES DE LOS CULTIVOS EN LA PROVINCIA DEL CHACO ENTRE 1951 Y 2000. Revista Geográfica Digital. IGUNNE. Facultad de Humanidades. UNNE. Año 11. N No 21. Enero - Junio 2014. ISSN 1668-5180. Resistencia, Chaco. 
It follows from this analysis that the winter frosts are more intense and frequent. However, frost most often generate severe damage, are the early and late frosts, ie, those that occur in autumn and spring respectively, although these are less intense than winter. Also, the damage generated in crops depend on the sensitivity and/or resistance to these low temperatures and phase of the life cycle in which they are each.

\section{KEY WORDS}

Frequency and duration of frost; agricultural productivity; Chaco. 
Revista Geográfica Digital. IGUNNE. Facultad de Humanidades. UNNE. Año 11. Nº 21. Enero - Junio 2014. ISSN 1668-5180. Resistencia, Chaco.

\section{INTRODUCCIÓN}

Los temas estudiados por la Climatología se entremezclan íntimamente con los hechos que se producen en la vida cotidiana. La influencia del clima en el modo de vivir y en las costumbres es actualmente tan grande como en la antigüedad y la agricultura, como actividad económica de relevancia, continúa dependiendo casi enteramente del clima y de las variaciones del tiempo.

La combinación particular de los elementos climáticos genera una determinada influencia en la actividad agrícola, ya que la variabilidad climática provoca la mayor parte de las fluctuaciones interanuales en el comportamiento y rendimiento de los cultivos, lo que implica que este fenómeno debe ser estudiado en forma local.

La helada, fenómeno meteorológico natural que ocurre cuando la temperatura del aire desciende a valores tan bajos que afecta a las plantas, provocando daños parciales o totales en las mismas, es una de las amenazas que azota permanentemente a la actividad agrícola por la magnitud de los daños que en ésta produce.

Para estudiar este fenómeno se cuenta con las fuentes de información que están a nuestro alcance y son de dos tipos: a) datos proporcionados por las Estadísticas Climatológicas del Servicio Meteorológico Nacional (SMN) de los 50 años en cuestión -desde la década 1951/60 hasta la de 1991/2000- en las que se hallan publicados datos del número medio de días con helada y de temperaturas mínimas mensuales y anuales de las estaciones meteorológicas del área objeto de estudio; b) datos suministrados por el Instituto Nacional de Tecnología Agropecuaria (INTA) y la Oficina de Riesgos Agropecuarios (ORA), referidos principalmente a las fechas de ocurrencia de las distintas fases del ciclo vital de los principales cultivos que se producen en el Chaco desde el período de siembra hasta el de cosecha.

El análisis de las heladas, de su duración y de su influencia sobre los cultivos es objeto de estudio de varias disciplinas, entre ellas de la Agronomía, de la Meteorología, de la Climatología, etc. pero es la Geografía la que le impregna a la investigación el enfoque holístico e integrador de tal forma de comprender el fenómeno de una manera global y no desde una única perspectiva.

De acuerdo con lo expuesto, el presente trabajo tiene por objetivos:

\section{Objetivos generales}

- Estudiar la influencia de las heladas en los principales cultivos de la provincia del Chaco en los últimos cincuenta años.

- Determinar las fechas de las heladas extremas, es decir, de las primeras (heladas tempranas) y de las últimas (heladas tardías).

\section{Objetivos específicos}

- Analizar la distribución espacial y temporal de las heladas tempranas y tardías en la provincia del Chaco.

- Determinar las áreas sujetas a mayor ocurrencia de heladas y su efecto en los cultivos, dentro del territorio provincial.

- Identificar los tipos de cultivos más afectados por las heladas y la fase del ciclo biológico en la que se encuentran.

Publicado en formato digital: Prof. María de los Ángeles Martínez Jiménez y Prof. Patricia Perla Snaider. LA OCURRENCIA DE HELADAS Y SU INFLUENCIA EN LAS FASES DE LOS CULTIVOS EN LA PROVINCIA DEL CHACO ENTRE 1951 Y 2000. Revista Geográfica Digital. IGUNNE. Facultad de Humanidades. UNNE. Año 11. № 21. Enero - Junio 2014. ISSN 1668-5180. Resistencia, Chaco. 
Revista Geográfica Digital. IGUNNE. Facultad de Humanidades. UNNE. Año 11. Nº 21. Enero - Junio 2014. ISSN 1668-5180. Resistencia, Chaco.

\section{METODOLOGÍA}

El logro de los objetivos señalados requiere el cumplimiento de las siguientes etapas metodológicas, dejando constancia que, en algunas oportunidades, dichas etapas pueden ser correlativas o simultáneas, según sea el desarrollo de los temas propuestos y la disponibilidad de la información.

1. Etapa de selección, recopilación y ordenamiento de la información: se ha trabajado con fuentes estadísticas y bibliográficas.

a) Estadísticas: Ios datos estadísticos de partida con los que contamos para iniciar y sondear el trabajo provienen de dos fuentes: a) los que cada 10 años aproximadamente recaba y publica el Servicio Meteorológico Nacional, dependiente de la Fuerza Aérea Argentina, a través de las Estadísticas Climatológicas de las décadas 1951-60, 1961-70, 1971-80, 1981-90 y 1991-2000, y b) el calendario del período de siembra hasta el de cosecha, en el que se indican las fechas en las que se inicia cada fase del ciclo biológico de los principales cultivos de la provincia del Chaco -girasol, maíz, algodón y sorgo (1)- suministrado por el Instituto Nacional de Tecnología Agropecuaria y la Oficina de Riesgos Agropecuarios dependiente de ésta institución.

b) Bibliográficas: selección y análisis de las contribuciones teóricas existentes, así como de otros enfoques referidos al tema, que sirvan de apoyo a la investigación. En este ítem, y considerando la bibliografía consultada, podemos nombrar entre obras de carácter general referidas a metodología de la investigación científica, de investigación en Geografía, como a las referidas a la Climatología, la Meteorología, Agroclimatología y Agronomía para abordar el estudio de las heladas.

2. Etapa de procesamiento de la información: la magnitud y diversidad de la información sobre los distintos aspectos a analizar, motiva la tarea de seleccionar y organizar el material estadístico para lograr un mejor aprovechamiento e interpretación de los mismos.

Las Estadísticas Climatológicas publicadas por el Servicio Meteorológico Nacional (S.M.N.) contienen valores referidos al número medio de días con helada (mensual y anual) y a la temperatura mínima absoluta, ambos registrados en un período de 50 años (1950 - 2000).

Dado que el ciclo ontogénico (2) de los cultivos se desarrolla en una época determinada, es decir durante el verano o, más precisamente, en el "período libre de heladas", más que el conocimiento de la frecuencia de este fenómeno nos interesó, en primer lugar, determinar las fechas de las primeras y de las últimas heladas, a los efectos de definir el período más adecuado para el desarrollo biológico del cultivo.

(1) Existen otros cultivos relevantes en la provincia, tales como el trigo (con sus variedades invernal y de primavera) y la soja (temprana y tardía, según la fecha de siembra). Éstos no fueron tenidos en cuenta en este trabajo ya que, en el caso del trigo, al ser un cultivo invernal no está tan influenciado por las heladas como aquellos que desarrollan su ciclo ontogénico en el resto de las estaciones; para el caso de la soja, debido a que su auge comienza a partir de la década del 90 y se intensifica en el 2000, no se lo consideró comparable con el resto de los cultivos tradicionales desde mediados del siglo pasado, ya que el período de análisis en esta investigación finaliza en el 2000.

(2) Hace referencia al ciclo de vida de una planta desde la germinación hasta su madurez fisiológica, en donde se aprecian los principales cambios externos e internos por los que atraviesa el cultivo.

Publicado en formato digital: Prof. María de los Ángeles Martínez Jiménez y Prof. Patricia Perla Snaider. LA OCURRENCIA DE HELADAS Y SU INFLUENCIA EN LAS FASES DE LOS CULTIVOS EN LA PROVINCIA DEL CHACO ENTRE 1951 Y 2000. Revista Geográfica Digital. IGUNNE. Facultad de Humanidades. UNNE. Año 11. No 21. Enero - Junio 2014. ISSN 1668-5180. Resistencia, Chaco. 
Revista Geográfica Digital. IGUNNE. Facultad de Humanidades. UNNE. Año 11. Nº 21. Enero - Junio 2014. ISSN 1668-5180. Resistencia, Chaco.

Como las heladas, desde un punto de vista climatológico, se definen por un registro de temperatura igual o inferior a cero grado $\left(0^{\circ} \mathrm{C}\right)$ dentro del abrigo meteorológico (ubicado a 1,50 m sobre el nivel del suelo) los datos de temperatura mínima absoluta de cada mes permiten calcular en forma aproximada las fechas en las que se registraron la primera y la última helada de cada década (Cfr. BRUNIARD et al., 2001). Dicho cálculo se realiza mediante la representación gráfica de las temperaturas mínimas absolutas y la temperatura de $0^{\circ} \mathrm{C}$ de todas las estaciones meteorológicas.

Las fechas de inicio y fin del período de heladas se estiman a partir de la intersección de la curva de la temperatura mínima absoluta con la línea de $0^{\circ} \mathrm{C}$ en el eje de las abscisas, en el cual se hallan reresentados los meses del año. El primer y el segundo punto de intersección en dicho eje, indican en forma aproximada las fechas de primera y última helada, respectivamente.

En total se han realizado 76 gráficos que corresponden a cada una de las estaciones meteorológicas del Chaco y provincias limítrofes y, a su vez, para cada una de las décadas. A modo de ejemplo se presenta el siguiente gráfico, a partir del cual se pudo determinar estimativamente:

- el período con heladas (que se registra cuando la temperatura es igual o inferior a $0^{\circ} \mathrm{C}$ ) y;

- las fechas de inicio y fin de las heladas.

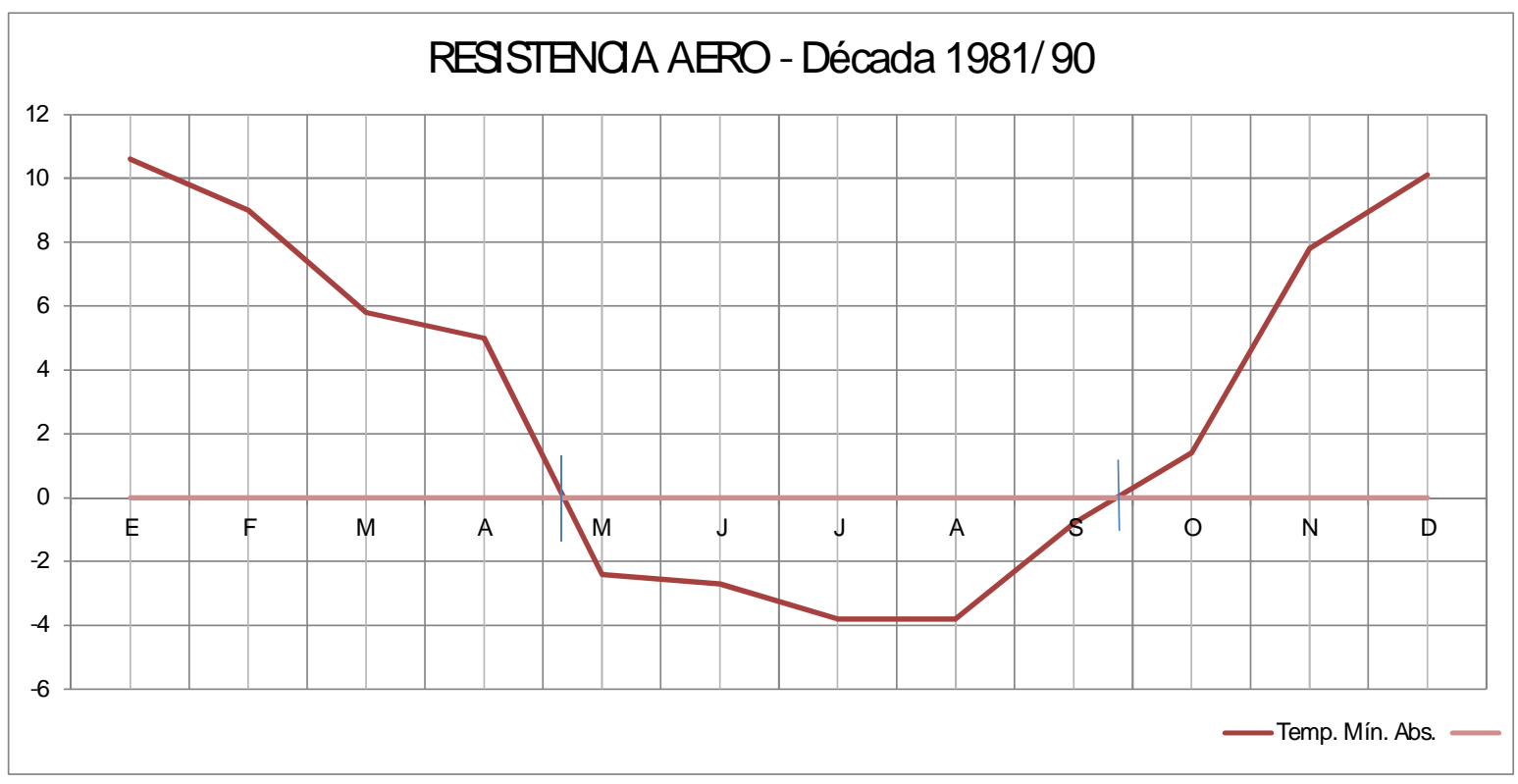

Fuente: Elaborado a partir de los datos de Temperatura Mínima Absoluta de las Estadísticas Climatológicas del S.M.N.

\begin{tabular}{|l|l|l|c|}
\hline Década & Estación Meteorológica & Fecha Primera Helada & Fecha Última Helada \\
\hline $1981 / 90$ & Resistencia AERO & 6 de mayo & 27 de septiembre \\
\hline
\end{tabular}

Una vez realizado este procedimiento para cada localidad y en cada década, se obtuvieron las fechas de la primera y de la última helada que fueron consignadas en la siguiente tabla junto con los datos de frecuencia media anual:

Publicado en formato digital: Prof. María de los Ángeles Martínez Jiménez y Prof. Patricia Perla Snaider. LA OCURRENCIA DE HELADAS Y SU INFLUENCIA EN LAS FASES DE LOS CULTIVOS EN LA PROVINCIA DEL CHACO ENTRE 1951 Y 2000. Revista Geográfica Digital. IGUNNE. Facultad de Humanidades. UNNE. Año 11. No 21. Enero - Junio 2014. ISSN 1668-5180. Resistencia, Chaco. 
Revista Geográfica Digital. IGUNNE. Facultad de Humanidades. UNNE. Año 11. Nº 21.

Enero - Junio 2014. ISSN 1668-5180. Resistencia, Chaco.

Tabla 1: Fecha de las primeras y últimas heladas y frecuencia anual (por década).

\begin{tabular}{|c|c|c|c|c|c|c|c|c|c|c|c|c|c|c|c|}
\hline \multirow[b]{2}{*}{$\begin{array}{l}\text { Estación } \\
\text { Meteorol. }\end{array}$} & \multicolumn{3}{|c|}{$51-60$} & \multicolumn{3}{|c|}{$61-70$} & \multicolumn{3}{|c|}{$71-80$} & \multicolumn{3}{|c|}{$81-90$} & \multicolumn{3}{|c|}{$91-2000$} \\
\hline & $\begin{array}{|ll|}1^{\circ} & H \\
(3) & \\
\end{array}$ & Ú H. & F.A & $1^{\circ} \mathrm{H}$. & Ú H. & F.A & $1^{\circ} \mathrm{H}$. & Ú H. & F.A & $1^{\circ} \mathrm{H}$. & Ú H. & F.A & $1^{\circ} \mathrm{H}$. & Ú H. & F.A \\
\hline $\begin{array}{l}\text { Col. } \text { Benítez } \\
\text { INTA }\end{array}$ & ----- & ----- & --- & $03-05$ & $16-09$ & 3,2 & $03-05$ & $14-09$ & 3,6 & 07-05 & $17-09$ & 2,3 & $26-05$ & 09-09 & 3 \\
\hline $\begin{array}{l}\text { Colonia } \\
\text { Castelli }\end{array}$ & 20-04 & 02-09 & 4,4 & 04-05 & 15-09 & 6,4 & ----- & ------ & ---- & ----- & ----- & --- & ----- & ----- & --- \\
\hline $\begin{array}{ll}\text { Las } & \text { Breñas } \\
\text { INTA } & \end{array}$ & ------ & ------ & --- & 21-04 & 25-09 & 8,7 & 04-05 & $30-09$ & 5,6 & 04-05 & $18-09$ & 3,6 & ---- & ----- & --- \\
\hline $\begin{array}{l}\text { P. R. Sáenz } \\
\text { Peña AERO }\end{array}$ & 04-05 & 11-09 & 8,9 & $03-05$ & $16-09$ & 5,3 & $14-05$ & 25-09 & 3,8 & $14-05$ & $15-09$ & 3,2 & $22-05$ & $13-09$ & 5,1 \\
\hline $\begin{array}{l}\text { P. R. Sáenz } \\
\text { Peña INTA }\end{array}$ & ----- & ------ & ---- & 01-05 & 23-09 & 7,6 & 01-05 & $07-10$ & 5,7 & 09-05 & $02-10$ & 4,5 & $19-05$ & 21-09 & 6,5 \\
\hline $\begin{array}{l}\text { Resistencia } \\
\text { AEROCLUB } \\
\end{array}$ & $20-06$ & $18-08$ & 2,2 & $03-06$ & 23-08 & 0,8 & 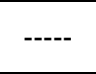 & ----- & --- & ----- & ------ & $\begin{array}{l}--- \\
-\end{array}$ & --- & ------ & --- \\
\hline $\begin{array}{l}\text { Resistencia } \\
\text { AERO }\end{array}$ & 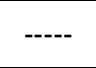 & ------ & ---- & $18-05$ & $30-08$ & 1,9 & 01-05 & $22-09$ & 4 & 06-05 & 27-09 & 3,4 & $22-05$ & 09-09 & 3,9 \\
\hline Villa Ángela & $15-05$ & 02-09 & 3,2 & 01-05 & $17-09$ & 6,7 & 05-05 & 23-09 & 5,5 & 08-05 & 28-09 & $s / d$ & ---- & ------ & --- \\
\hline
\end{tabular}

Fuente: Elaborado a partir de los datos de las Estaciones Climatológicas del S.M.N. (Décadas 1951-60, 1961-70, 1971-80, 1981-90 y 1991-2000).

Por su parte, con los datos obtenidos de la Oficina de Riesgos Agropecuarios (O.R.A.) y del Instituto Nacional de Tecnología Agropecuaria (I.N.T.A.) se elaboraron:

a) Un cuadro (Tabla 2) en el que figura el calendario con las fechas aproximadas de siembra, emergencia de la planta y cosecha de los principales cultivos del Chaco.

Tabla 2: Calendario de siembra y cosecha de los principales cultivos del Chaco:

\begin{tabular}{|c|c|c|c|c|c|c|c|c|c|c|c|c|c|c|c|}
\hline CULTIVO & $E$ & $\mathbf{F}$ & M & A & M & J & J & A & & s & & ) & $\mathbf{N}$ & & D \\
\hline $\begin{array}{l}\text { Algodón } \\
\text { Temprana }\end{array}$ & & & & 6 & & & & & & & & $\begin{array}{l}2 \\
3\end{array}$ & & & \\
\hline $\begin{array}{l}\text { Algodón } \\
\text { Tardía }\end{array}$ & & & & 29 & & & & & & & & & & & \\
\hline $\begin{array}{l}\text { Sorgo } \\
\text { Grano (4) }\end{array}$ & & $s / f$ & & & & & & & & s/ & & & & & \\
\hline Maíz 1º & 28 & & & & & & & & & \begin{tabular}{|l|}
1 \\
0 \\
\end{tabular} & & & & & \\
\hline Maíz $2^{\circ}$ & 8 & & & & 15 & & & & & & & & & & 30 \\
\hline Girasol $1^{\circ}$ & & & & & & & & & 8 & & & & & & \\
\hline Girasol $2^{\circ}$ & 28 & & & & & & & & & & & & & & \\
\hline
\end{tabular}

Fechas de inicio de:

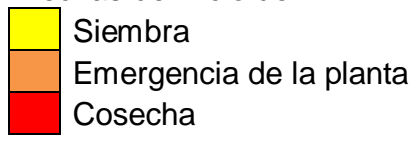

Fuente: Elaborado a partir de los datos publicados por la O.R.A y el I.N.T.A.

(3) $1^{\circ}$ H.: Primera helada. Ú H.: Última helada. F.A: Frecuencia anual de heladas.

(4) Del cultivo de sorgo no se poseen los datos de las fechas exactas de inicio de siembra, emergencia y cosecha, sólo se posee la información del mes en el que éstos ocurren.

Publicado en formato digital: Prof. María de los Ángeles Martínez Jiménez y Prof. Patricia Perla Snaider. LA OCURRENCIA DE HELADAS Y SU INFLUENCIA EN LAS FASES DE LOS CULTIVOS EN LA PROVINCIA DEL CHACO ENTRE 1951 Y 2000. Revista Geográfica Digital. IGUNNE. Facultad de Humanidades. UNNE. Año 11. No 21. Enero - Junio 2014. ISSN 1668-5180. Resistencia, Chaco. 
Revista Geográfica Digital. IGUNNE. Facultad de Humanidades. UNNE. Año 11. Nº 21. Enero - Junio 2014. ISSN 1668-5180. Resistencia, Chaco.

b) Un cuadro donde se combinan los datos de ocurrencia de heladas con la fecha de inicio de las fases del ciclo de los cultivos, consignados en la siguiente tabla:

Tabla 3: Fechas de Fenología de los cultivos del Chaco y período con heladas (5).

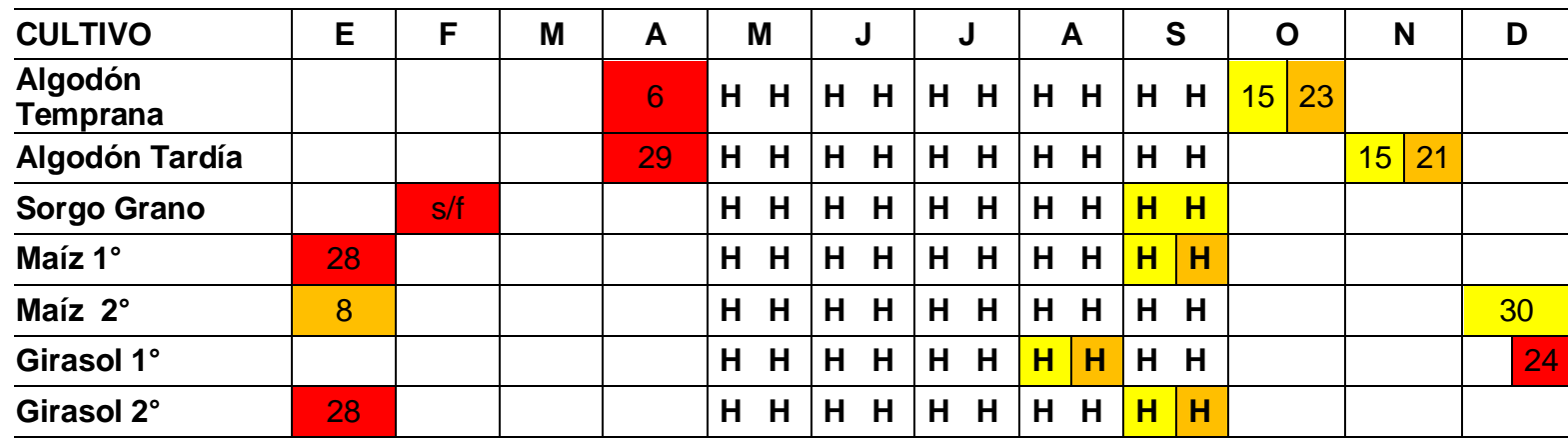

Fechas de inicio de:

\begin{tabular}{|l|l}
\hline & $\begin{array}{l}\text { Siembra } \\
\text { Emergencia de la planta } \\
\text { Cosecha }\end{array}$ \\
\cline { 1 - 1 } H H & $\begin{array}{l}\text { Período con heladas } \\
y\end{array}$
\end{tabular}

Fuente: Elaborado a partir de los datos publicados por la O.R.A., el INTA y los datos de las estadísticas Climatológicas del S.M.N. (décadas 1951-60, 1961-70, 1971-80, 1981-90 y 1991-2000).

c) Un cuadro (tabla 4: Fechas extremas de heladas y fases del cultivo. Ver en el apartado RESULTADOS) donde figuran el período del año en el que se producen heladas, o sea las fechas en las que comienza y finaliza este fenómeno meteorológico y las fechas en las que se inicia cada fase del ciclo ontogénico de cada cultivo chaqueño.

3. Etapa de representación cartográfica: una vez seleccionada y procesada la información estadística se procedió a la elaboración cartográfica que permitió la visualización de las características espaciales.

A partir de los datos de heladas y de temperaturas mínimas absolutas de las estaciones meteorológicas de la provincia del Chaco (y algunas estaciones ubicadas en las provincias limítrofes), contenidos en las Estadísticas Climatológicas del SMN de los períodos seleccionados, se elaboraron las representaciones cartográficas en formato vectorial, de tipo isopléticos, de:

a) la distribución espacial de frecuencia de heladas para cada década analizada y

b) la variación estacional del meteoro a partir de la representación de las fechas de las heladas tempranas y tardías (fecha de la primer y última helada).

(5) Para confeccionar esta tabla se ha tomado el mes extremo en que se producen heladas (tanto la primera como la última) durante las 5 décadas en estudio.

Publicado en formato digital: Prof. María de los Ángeles Martínez Jiménez y Prof. Patricia Perla Snaider. LA OCURRENCIA DE HELADAS Y SU INFLUENCIA EN LAS FASES DE LOS CULTIVOS EN LA PROVINCIA DEL CHACO ENTRE 1951 Y 2000. Revista Geográfica Digital. IGUNNE. Facultad de Humanidades. UNNE. Año 11. № 21. Enero - Junio 2014. ISSN 1668-5180. Resistencia, Chaco. 
Revista Geográfica Digital. IGUNNE. Facultad de Humanidades. UNNE. Año 11. № 21.

Enero - Junio 2014. ISSN 1668-5180. Resistencia, Chaco.

Se ha trabajado con el software propietario de la empresa ESRI: el ArcGis 9.3 para la generación de la cartografía, utilizando el procedimiento de interpolación para generar las isocrías (líneas que unen puntos de igual frecuencia de heladas) e isocronas (líneas que unen puntos con la misma fecha en que se produjo el evento), también llamadas isolíneas fechadas. El método de interpolación que se aplicó fue IDW (Ponderación de distancia inversa), herramienta del ArcGIS que estima los valores de las celdas calculando promedios de los datos de la muestra en la vecindad de cada celda de procesamiento. Cuanto más cerca está un punto del centro de la celda que se está estimando, más influencia o peso tendrá en el proceso de cálculo del promedio (Para ampliar consultar en ArcGIS Resourse Center. En: http://help.arcgis.com/es/arcgisdesktop/10.0/help/index.html)

Los mapas de isolíneas (isocrías e isocronas) que se confeccionaron fueron los siguientes:

- -Frecuencia media anual de días con helada para cada década en estudio.

- $\quad$-Fecha en que se registra la primera helada para cada década en estudio.

- -Fecha en que se registra la última helada para cada década en estudio.

4. Etapa de análisis e interpretación y de formulación de resultados: el análisis e interpretación de la información estadística, cartográfica y bibliográfica de los temas estudiados, posibilitaron la elaboración y redacción de los resultados alcanzados, tal como se los presenta a continuación.

\section{RESULTADOS}

\section{A. Los cultivos en la Provincia del Chaco}

En el mapa de la figura 1 se muestra la distribución geográfica de los principales cultivos de nuestra provincia durante el quinquenio 1977/78-1981/82.

La estructura agrícola de la provincia del Chaco se basa en la producción de varios cultivos principales, tales como el algodón, el maíz, el sorgo y el girasol, entre otros. Estos son cultivos anuales -completan su ciclo vital en el transcurso de un año o en menos tiempo- y estivales -especies de estación cálida, que no resisten al frío y que pueden dejar de crecer a temperaturas bajas-; es por ello que la mayoría de dichos cultivos se siembran en primavera, y florecen y fructifican en pleno verano o a fines del mismo.

En el Chaco la práctica agrícola anual de estos cultivos se clasifica según las fechas en las que se produce la siembra, lo cual fue consignado en la Tabla 2: Calendario de siembra y cosecha de los principales cultivos del Chaco.

a) el algodón se siembra en forma temprana a mediados de octubre y se cosecha a principios de abril y en forma tardía se siembra a mediados de noviembre y se cosecha a fines de abril.

b) el sorgo (en grano) se siembra en septiembre y se comienza a cosechar en febrero aproximadamente.

c) el maíz en grano se clasifica en: maíz de primera que se siembra a principios de septiembre y se cosecha a fines de enero y el de segunda se siembra a fines de diciembre y se cosecha a mediados de mayo.

d) el girasol de primera se siembra a principios de agosto y se cosecha a fines de diciembre y el de segunda se siembra a mediados de septiembre y se cosecha a fines de enero.

Publicado en formato digital: Prof. María de los Ángeles Martínez Jiménez y Prof. Patricia Perla Snaider. LA OCURRENCIA DE HELADAS Y SU INFLUENCIA EN LAS FASES DE LOS CULTIVOS EN LA PROVINCIA DEL CHACO ENTRE 1951 Y 2000. Revista Geográfica Digital. IGUNNE. Facultad de Humanidades. UNNE. Año 11. No 21. Enero - Junio 2014. ISSN 1668-5180. Resistencia, Chaco. 
Revista Geográfica Digital. IGUNNE. Facultad de Humanidades. UNNE. Año 11. № 21. Enero - Junio 2014. ISSN 1668-5180. Resistencia, Chaco.

Figura 1: Principales cultivos de la Provincia del Chaco. Año 1982.

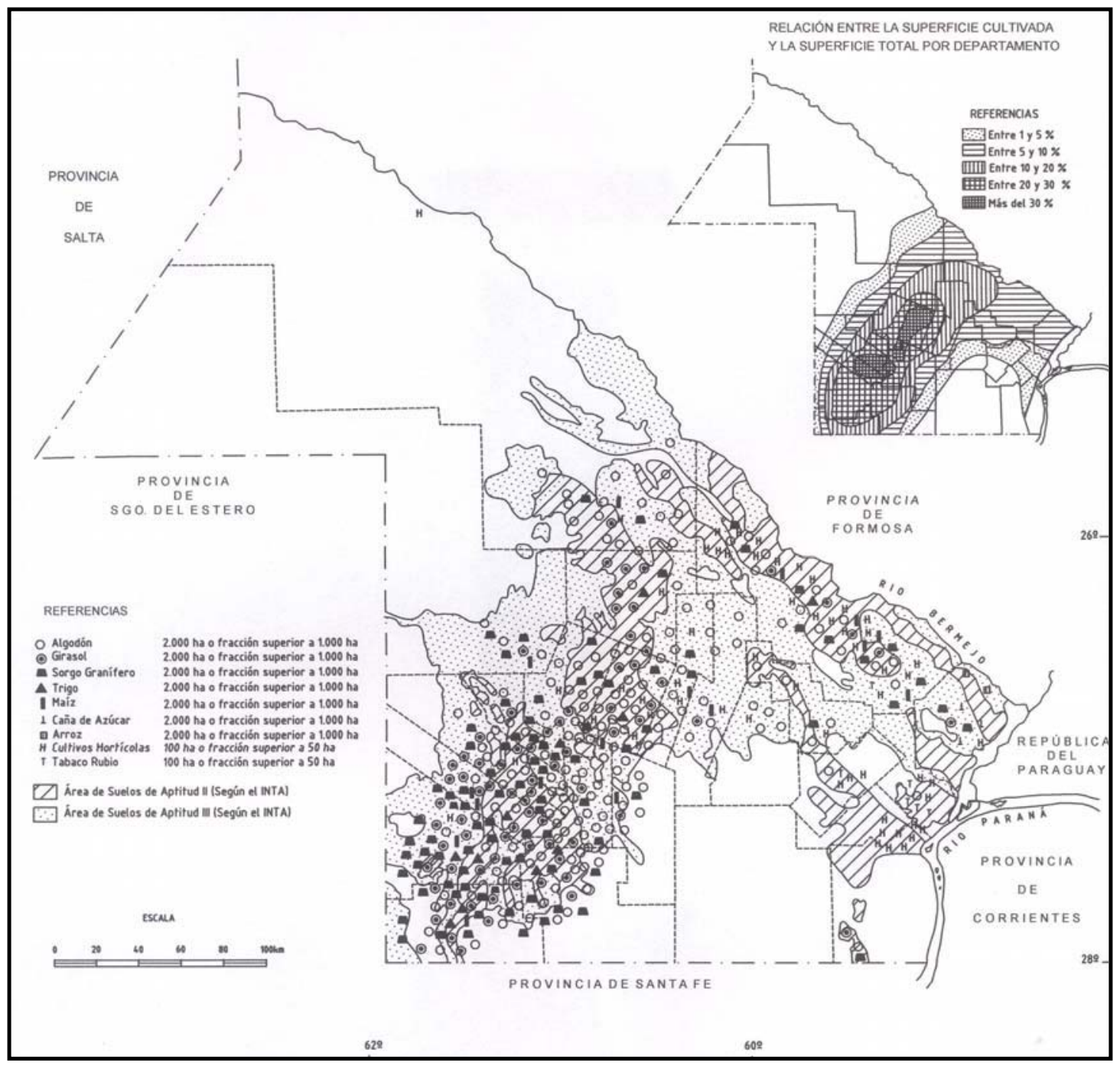

Fuente: MANOILLOF, Raúl, PEREZ, María E. y REY, Walter (Dir.) y equipo (2009) "Atlas Geográfico de la provincia del Chaco. Tomo III: Las Actividades Primarias". En: Revista Geográfica No 16. Instituto de Geografía, Facultad de Humanidades. Universidad Nacional del Nordeste. Resistencia, Chaco. República Argentina. Plancha No 16.

\section{B. Las heladas meteorológicas en la Provincia del Chaco}

Es importante aclarar que, teniendo en cuenta la temperatura del aire, las heladas pueden clasificarse de dos maneras: por un lado, las heladas meteorológicas -que serán abordadas en esta publicación- son aquellas que ocurren cuando el termómetro de mínima ubicado en el abrigo meteorológico (a $1,50 \mathrm{~m}$ del suelo) registra una temperatura de $0^{\circ} \mathrm{C}$ o inferior; y por otro, las consideradas heladas agrometeorológicas ocurren cuando el termómetro de mínima del abrigo indica una temperatura de $3^{\circ}$ aproximadamente, ya que se considera que la superficie del suelo a la intemperie puede alcanzar una temperatura de $0^{\circ} \mathrm{C}$ o menos. Además, la ocurrencia de una helada está asociada a la combinación de otros factores como: cielo despejado, aire en calma, humedad relativa del aire, tipo de suelo y vegetación, etc.

Según Bruniard et al. (2001: 1) "El fenómeno de la helada en el ámbito subtropical argentino se debe a "empujes de aire polar" -masa fría de origen meridional-, y cubre una buena parte del año, entre cuatro y cinco meses, de modo que deja libre un período cronológicamente limitado para la

Publicado en formato digital: Prof. María de los Ángeles Martínez Jiménez y Prof. Patricia Perla Snaider. LA OCURRENCIA DE HELADAS Y SU INFLUENCIA EN LAS FASES DE LOS CULTIVOS EN LA PROVINCIA DEL CHACO ENTRE 1951 Y 2000. Revista Geográfica Digital. IGUNNE. Facultad de Humanidades. UNNE. Año 11. No 21. Enero - Junio 2014. ISSN 1668-5180. Resistencia, Chaco. 
Revista Geográfica Digital. IGUNNE. Facultad de Humanidades. UNNE. Año 11. № 21.

Enero - Junio 2014. ISSN 1668-5180. Resistencia, Chaco.

práctica [de los cultivos], cuyo ciclo biológico debe adecuarse al conjunto de circunstancias climatológicas que se desarrollan dentro de ese período determinado"

Los datos de frecuencia media anual (número medio de días con helada al año), publicados en las Estadísticas Climatológicas para cada una de las décadas, fueron representados a través de la cartografía de isocrías (líneas que unen igual valor de frecuencia de heladas), a fin de detectar las variaciones espaciales del meteoro en estudio en cada una de las décadas analizadas (figuras 2 a 6 ). En dicha cartografía se observan, en general, diferencias entre el oriente y el occidente provincial, que consisten en un menor número medio de días con helada en el oriente, en comparación con el occidente donde éste fenómeno suele ser más frecuente. Los guarismos oscilan entre 1 o 2 días con helada al año en el Este del Chaco, hasta los 6, 7 u 8 días con registro de heladas por año (en promedio para cada década) en el centro y Oeste de la provincia.

Si se analizan los mapas temáticos por separado, se advierte que, tanto las décadas 1951-60 y 1961-70, como la de 1991-2000, son las que agrupan en el centro y occidente de la provincia el mayor número medio de días con helada (superior a 7 días) en comparación con el sector oriental en el que la frecuencia disminuye hasta sólo 1 día (Ver figuras 2, 3 y 6). En las décadas restantes (197180 y 1981-90) se advierten similares diferencias en la distribución del fenómeno entre el oriente y occidente provincial, no obstante, existe una disminución en la frecuencia media que oscila entre 1 ó 2 y 6 (Ver figuras 4 y 5).

Tabla 4: Valores de máxima y mínima frecuencia de heladas registrados en el Chaco en cada década estudiada, con su correspondiente localización dentro de la provincia.

\begin{tabular}{|c|c|c|c|c|c|}
\hline \multirow{2}{*}{ DÉCADA } & \multicolumn{2}{|c|}{ MÁXIMA FRECUENCIA } & \multicolumn{2}{|c|}{ MÍNIMA FRECUENCIA } & DIFERENCIAS DE \\
\cline { 2 - 5 } & Valor & Lugar & Valor & Lugar & FRECUENCIA \\
\hline $\mathbf{1 9 5 1 - 1 9 6 0}$ & 8.9 & Centro & 2.2 & Oriente & 6.7 \\
\hline $\mathbf{1 9 6 1 - 1 9 7 0}$ & 8.7 & Sudoeste & 0.8 & Oriente & 7.9 \\
\hline $\mathbf{1 9 7 1 - 1 9 8 0}$ & 5.7 & Centro/ Sudoeste & 3.6 & Oriente & 2.1 \\
\hline $\mathbf{1 9 8 1 - 1 9 9 0}$ & 4.5 & Centro & 2.3 & Oriente & 2.2 \\
\hline $\mathbf{1 9 9 1 - 2 0 0 0}$ & 6.5 & Centro & 3.0 & Oriente & 3.5 \\
\hline
\end{tabular}

Fuente: Elaborado a partir de los datos publicados por las estadísticas Climatológicas del S.M.N. (décadas 195160, 1961-70, 1971-80, 1981-90 y 1991-2000).

A modo de síntesis, en la tabla 4 se han volcado los mayores y menores valores de frecuencia de heladas que se hayan registrado dentro de la provincia del Chaco en cada una de las décadas analizadas; junto con la localización aproximada de la/s estación/nes meteorológicas donde se hayan producido la mayor y menor cantidad de número de días con helada en el espacio provincial. En la última columna se presentan las diferencias entre la máxima y mínima frecuencia, es decir, denota la variación espacial del fenómeno. Se obtuvieron las siguientes características:

- La mayor cantidad de días con helada al año en la provincia y a lo largo del período de estudio ronda entre los 4,5 y 9 (en promedio por década) y son registrados en el centro y suroeste del Chaco.

- Las menores frecuencias de helada al año en la provincia y a lo largo del período de estudio oscilan entre 0,8 y 3,6 días, en promedio por década, y sus registros se localizan en el oriente del Chaco.

- Las mayores diferencias entre la máxima y mínima frecuencia se observan en las dos primeras décadas, siendo casi 4 veces mayor que las variaciones presentadas en la tercer y cuarta década. Esa variación pueden advertirse también en la cartografía que se presenta a continuación.

Publicado en formato digital: Prof. María de los Ángeles Martínez Jiménez y Prof. Patricia Perla Snaider. LA OCURRENCIA DE HELADAS Y SU INFLUENCIA EN LAS FASES DE LOS CULTIVOS EN LA PROVINCIA DEL CHACO ENTRE 1951 Y 2000. Revista Geográfica Digital. IGUNNE. Facultad de Humanidades. UNNE. Año 11. No 21. Enero - Junio 2014. ISSN 1668-5180. Resistencia, Chaco. 
Revista Geográfica Digital. IGUNNE. Facultad de Humanidades. UNNE. Año 11. № 21.

Enero - Junio 2014. ISSN 1668-5180. Resistencia, Chaco.

Figura 2: Frecuencia media anual de días con helada. Década 1951-1960.

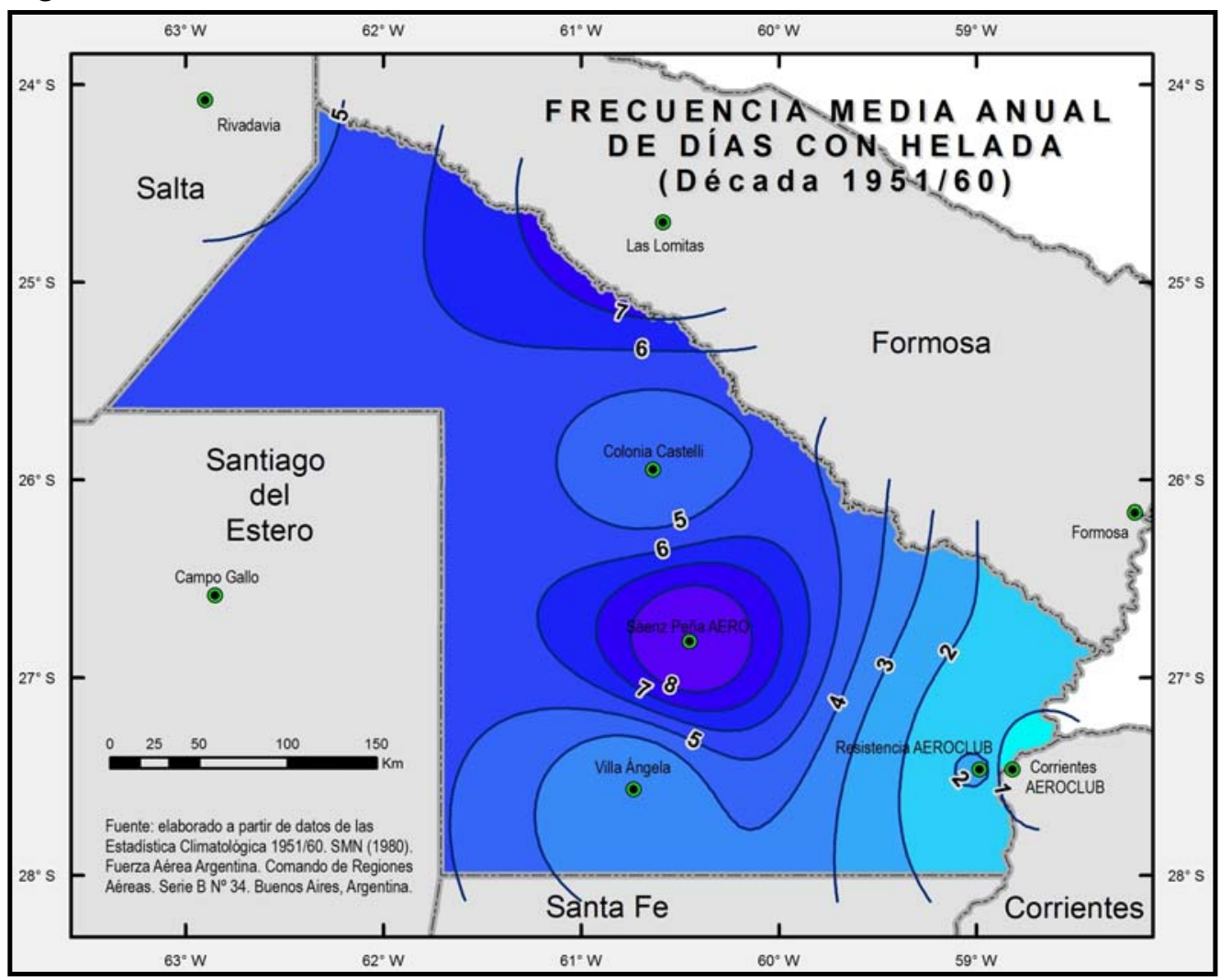

Figura 3: Frecuencia media anual de días con helada. Década 1961-1970.

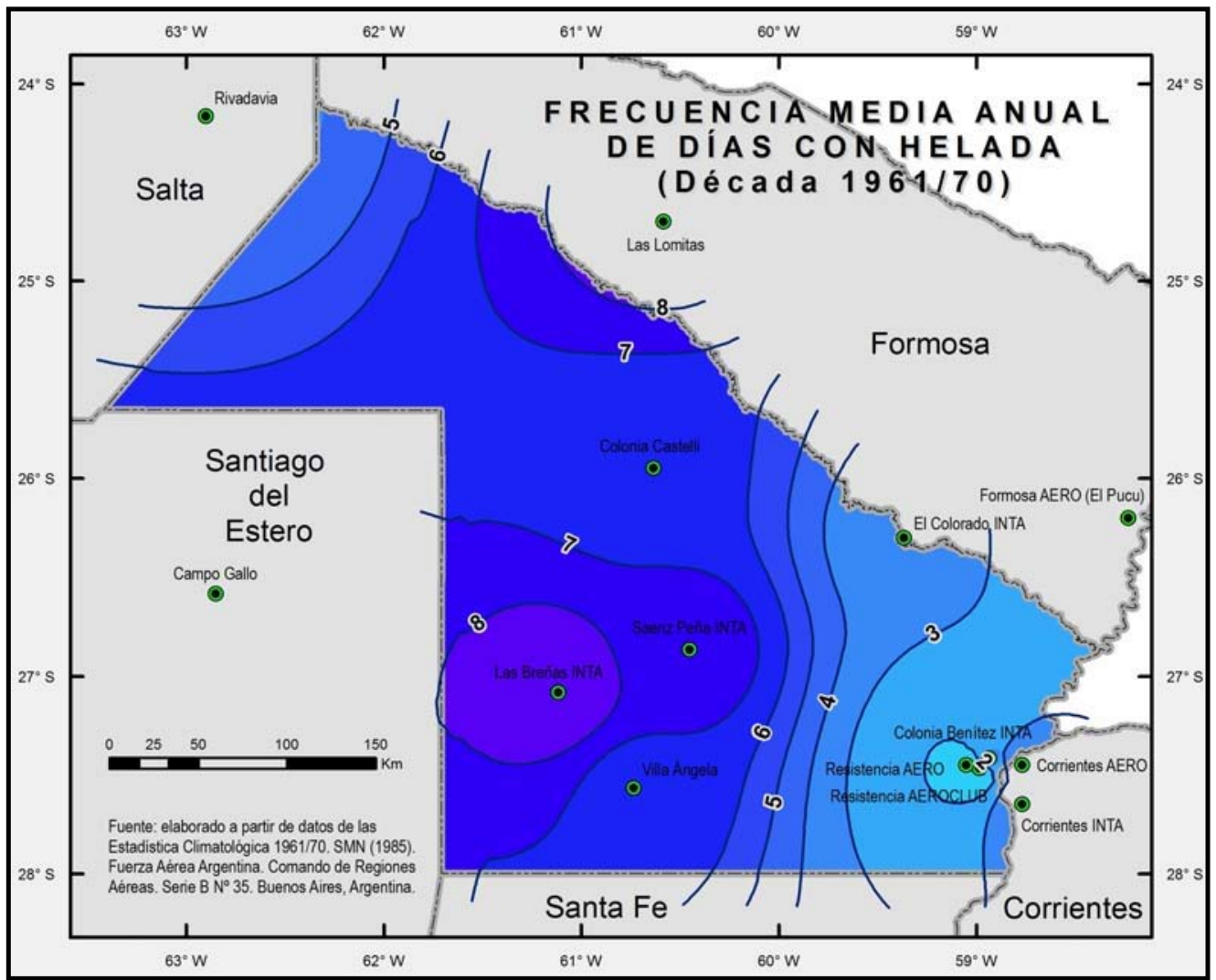

Publicado en formato digital: Prof. María de los Ángeles Martínez Jiménez y Prof. Patricia Perla Snaider. LA OCURRENCIA DE HELADAS Y SU INFLUENCIA EN LAS FASES DE LOS CULTIVOS EN LA PROVINCIA DEL CHACO ENTRE 1951 Y 2000. Revista Geográfica Digital. IGUNNE. Facultad de Humanidades. UNNE. Año 11. No 21. Enero - Junio 2014. ISSN 1668-5180. Resistencia, Chaco. 
Revista Geográfica Digital. IGUNNE. Facultad de Humanidades. UNNE. Año 11. № 21.

Enero - Junio 2014. ISSN 1668-5180. Resistencia, Chaco.

Figura 4: Frecuencia media anual de días con helada. Década 1971-1980.

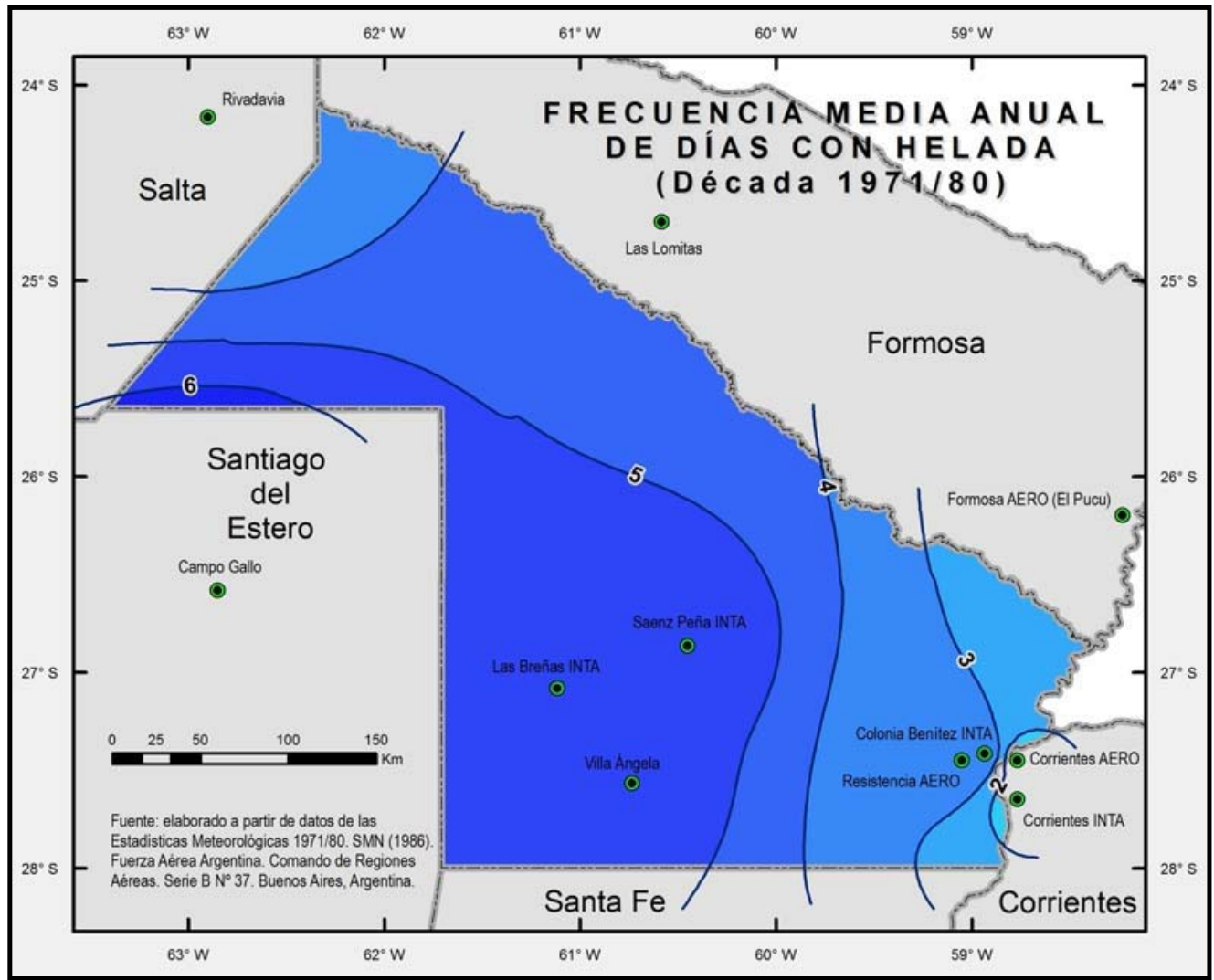

Figura 5: Frecuencia media anual de días con helada. Década 1981-1990.

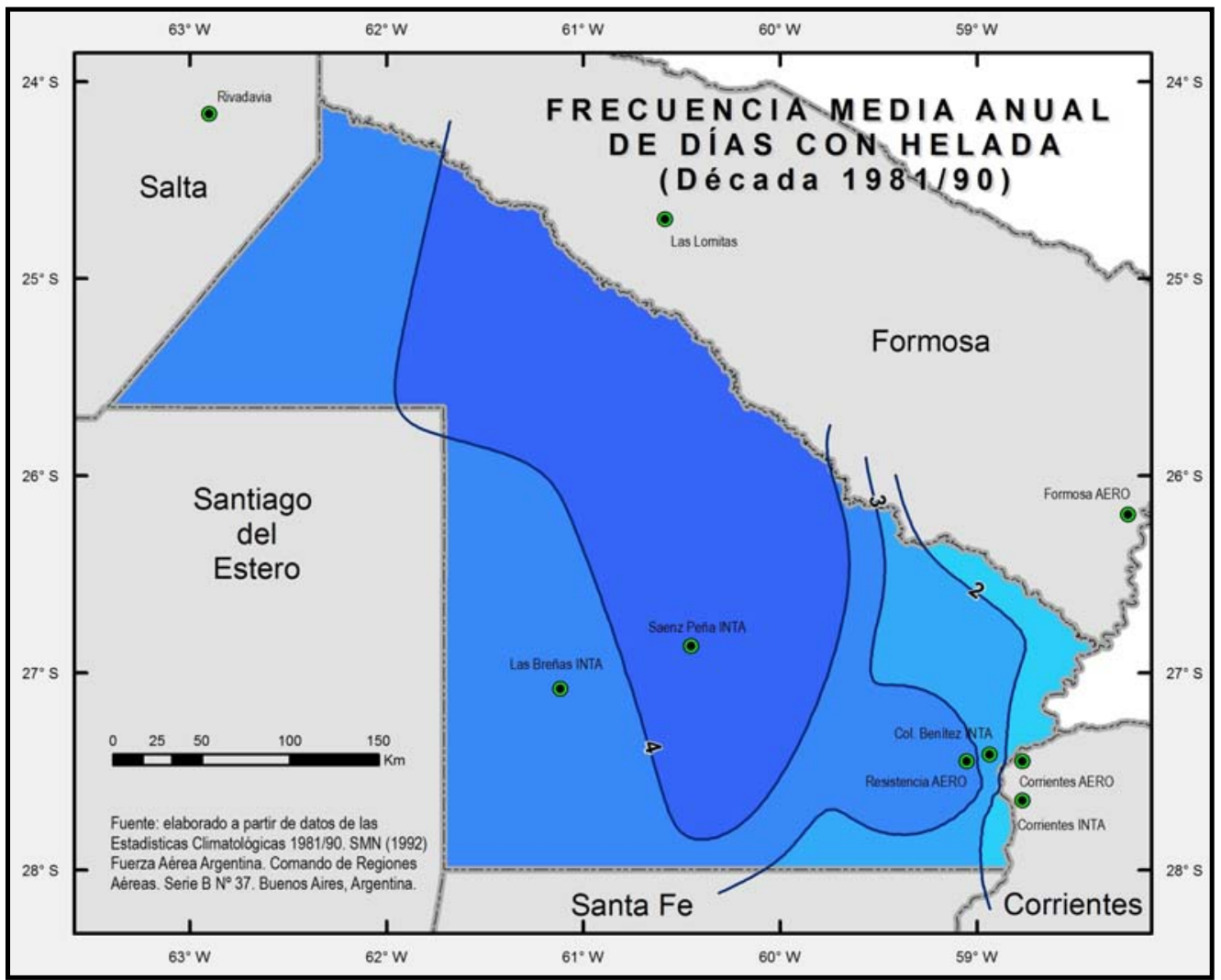

Publicado en formato digital: Prof. María de los Ángeles Martínez Jiménez y Prof. Patricia Perla Snaider. LA OCURRENCIA DE HELADAS Y SU INFLUENCIA EN LAS FASES DE LOS CULTIVOS EN LA PROVINCIA DEL CHACO ENTRE 1951 Y 2000. Revista Geográfica Digital. IGUNNE. Facultad de Humanidades. UNNE. Año 11. No 21. Enero - Junio 2014. ISSN 1668-5180. Resistencia, Chaco. 
Figura 6: Frecuencia media anual de días con helada. Década 1991-2000.

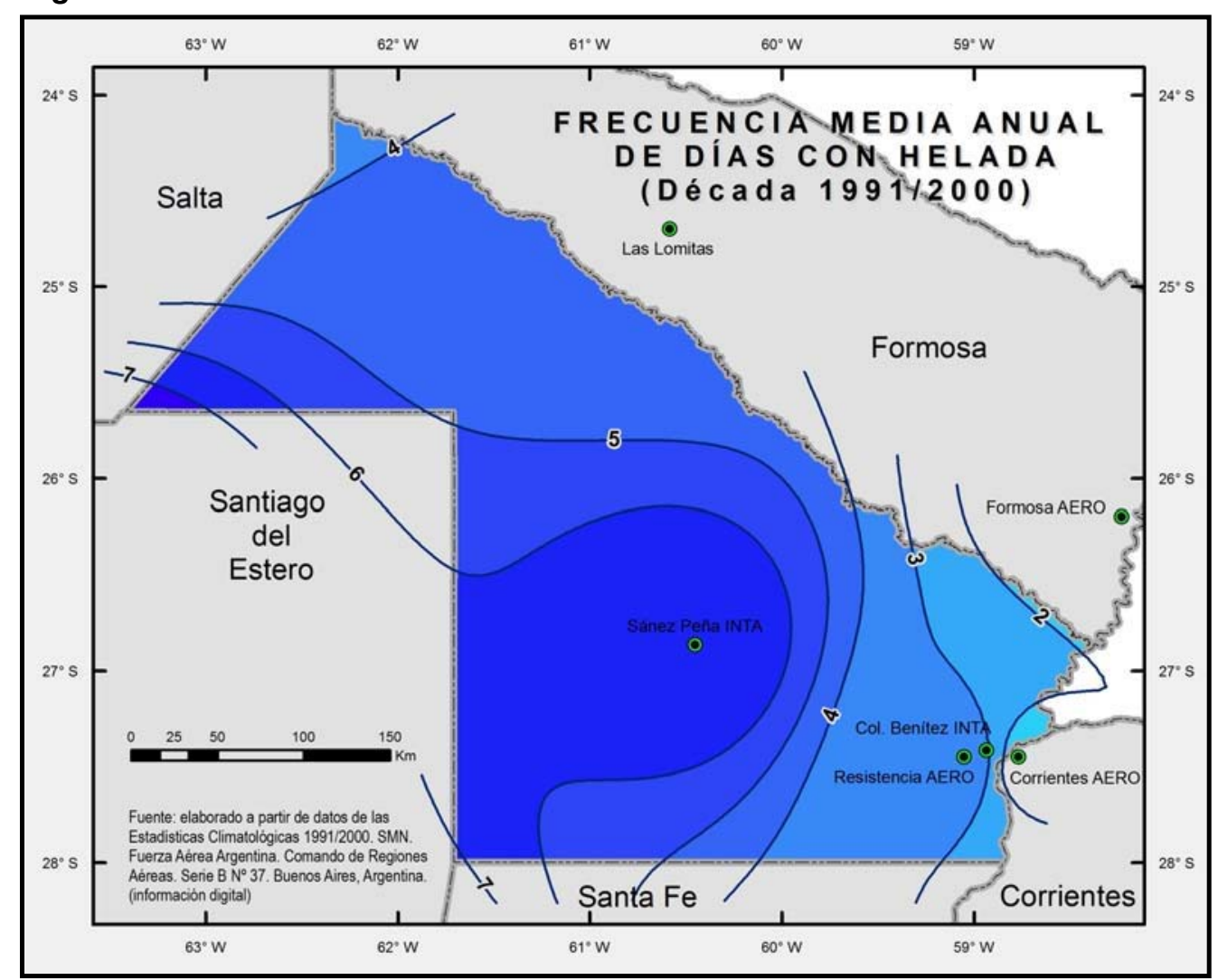

Según lo explican Bruniard et al. (2001), uno de los factores determinantes en esta diferenciación espacial tiene que ver con la distribución de la humedad atmosférica, ya que en la región oriental, la alta humedad relativa del aire genera durante la noche un intenso proceso de condensación (rocío) con la consiguiente liberación del calor latente, proceso que atenúa el enfriamiento nocturno del aire por irradiación reduciendo así el peligro de heladas y también su frecuencia, en contraposición con las áreas de menor contenido de humedad del sector occidental de la provincia.

Además, éstos mismos autores opinan que "...las masas de aire frío que producen heladas tienen mayor espesor en el oeste -contenidas en su flanco occidental por la pared orográfica que impide su expansión lateral- y tienden por ello a conservar sus propiedades de origen; mientras que en las planicies orientales el aire frío se extiende superficialmente, pierde espesor y se desnaturaliza más fácilmente en contacto con el suelo". (BRUNIARD et al. 2001: 2).

Es preciso aclarar que, como la ocurrencia de heladas es un evento climático que está íntimamente relacionado con la circulación general de la atmósfera, puesto que depende del ingreso de masas de aire, la variabilidad interanual de dichos ingresos, hace que en algunos años la probabilidad de que se produzcan temperaturas inferiores a $0^{\circ} \mathrm{C}$ sea muy reducida y en algunos lugares puedan no registrarse. (Cfr. BRUNIARD et al., 2001). En torno a ello, Burgos (1963: 83) sostiene que "...la falta de regularidad cronológica en la ocurrencia de heladas da al fenómeno un carácter de riesgo para la agricultura". 
Revista Geográfica Digital. IGUNNE. Facultad de Humanidades. UNNE. Año 11. № 21. Enero - Junio 2014. ISSN 1668-5180. Resistencia, Chaco.

\section{Duración de las heladas}

Las heladas ocurren con mayor frecuencia e intensidad en determinadas épocas del año, como ser en la estación invernal, y es por ello que la práctica agrícola de los cultivos anuales estivales tiende a realizarse en el período "libre de heladas". Además, como lo aseguran De Fina y Ravelo (1973: 194) "...las heladas que se registran durante el invierno, generalmente son las menos dañinas, pues las plantas en esa época, por hallarse en estado de reposo invernal, acusan poca sensibilidad a los fríos...".

Sin embargo, cuando se producen ciertas circunstancias que pueden provocar una mayor disminución de la temperatura fuera de la estación invernal, las heladas pueden adelantarse o atrasarse en su período habitual registrándose heladas que se consideran como tempranas $o$ tardías, respectivamente. Las primeras se denominan así porque se producen antes de que llegue el invierno, es decir a mediados o fines del otoño y las segundas una vez terminado el mismo, es decir, a principios o en plena primavera.

La mayoría de los cultivos de nuestra provincia, no se ven afectados por las heladas de invierno -que son las más intensas- sino que son las heladas que se producen en forma temprana o tardía las que con mayor frecuencia generan daños en los mismos. Es por ello que, según lo menciona Burgos (1963: 3) "las heladas primaverales y otoñales deben caracterizarse más por la época o fecha en que se producen que por su intensidad". De allí se desprende la necesidad de conocer las fechas extremas de ocurrencia de las primeras y últimas heladas, datos que fueron consignados en la Tabla 1: Fecha de las primeras y últimas heladas y frecuencia (por década). Dicha tabla fue representada cartográficamente en los mapas de las figuras 7 a 16.

El período con heladas en la provincia del Chaco se extiende, en general, desde fines de otoño hasta comienzos de primavera -con algunas variaciones en determinadas localidades y décadas-; además se observa, en líneas generales, que el oriente húmedo de la provincia se caracteriza por tener el período de heladas más breve en comparación con el occidente árido, donde el fenómeno es más frecuente y más extendido en el tiempo.

\section{Primera helada}

En la cartografía donde se representan las isocronas de las fechas de las primeras heladas (figuras 7 a 11) se advierte, en general, que el fenómeno se registra con antelación en el Oeste provincial (entre la segunda quincena de abril y la primera quincena de mayo), mientras que en el oriente las primeras heladas se producen entre 15 y 30 días después.

Además, en la primera década de estudio correspondiente al período 1951-1960 (figura 7) se advierte que las heladas otoñales son más tempranas principalmente en la zona central y Oeste de la provincia (las primeras haladas se registran entre mediados de abril y mediados de mayo); y a medida que nos dirigimos hacia el oriente se observa un retraso en las fechas de las primeras heladas (primer quincena de julio), siendo éste aumento prácticamente en sentido longitudinal. Sin embargo, en las décadas siguientes, no se observa un gradiente tan acentuado ya que las primeras heladas comienzan a producirse a lo largo de todo el mes de mayo en todo el territorio provincial, salvo en la década de 1961-70 en la que las heladas en el Sudoeste de la provincia se producen tempranamente, a fines de abril (figura 8). Por otra parte, en las dos décadas siguientes (figuras 9 y 10) la primera helada se produce en la primera quincena de mayo, mientras que en la década 1991/2000 (figura 11) comienzan más tarde, a fines de mayo.

Publicado en formato digital: Prof. María de los Ángeles Martínez Jiménez y Prof. Patricia Perla Snaider. LA 
Revista Geográfica Digital. IGUNNE. Facultad de Humanidades. UNNE. Año 11. № 21.

Enero - Junio 2014. ISSN 1668-5180. Resistencia, Chaco.

Figura 7: Fecha de la primera helada. Década 1951-1960.

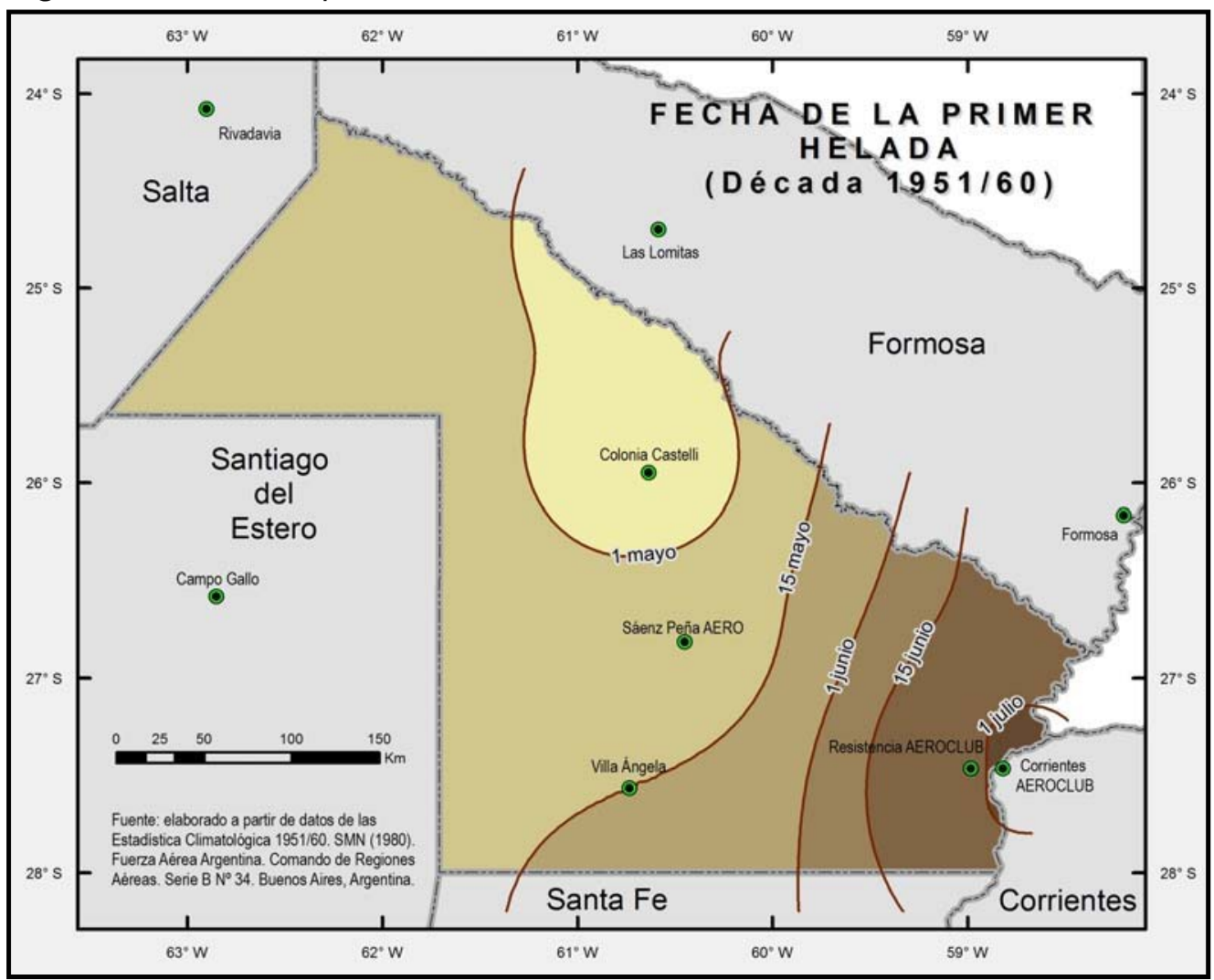

Figura 8: Fecha de la primera helada. Década 1961-1970.

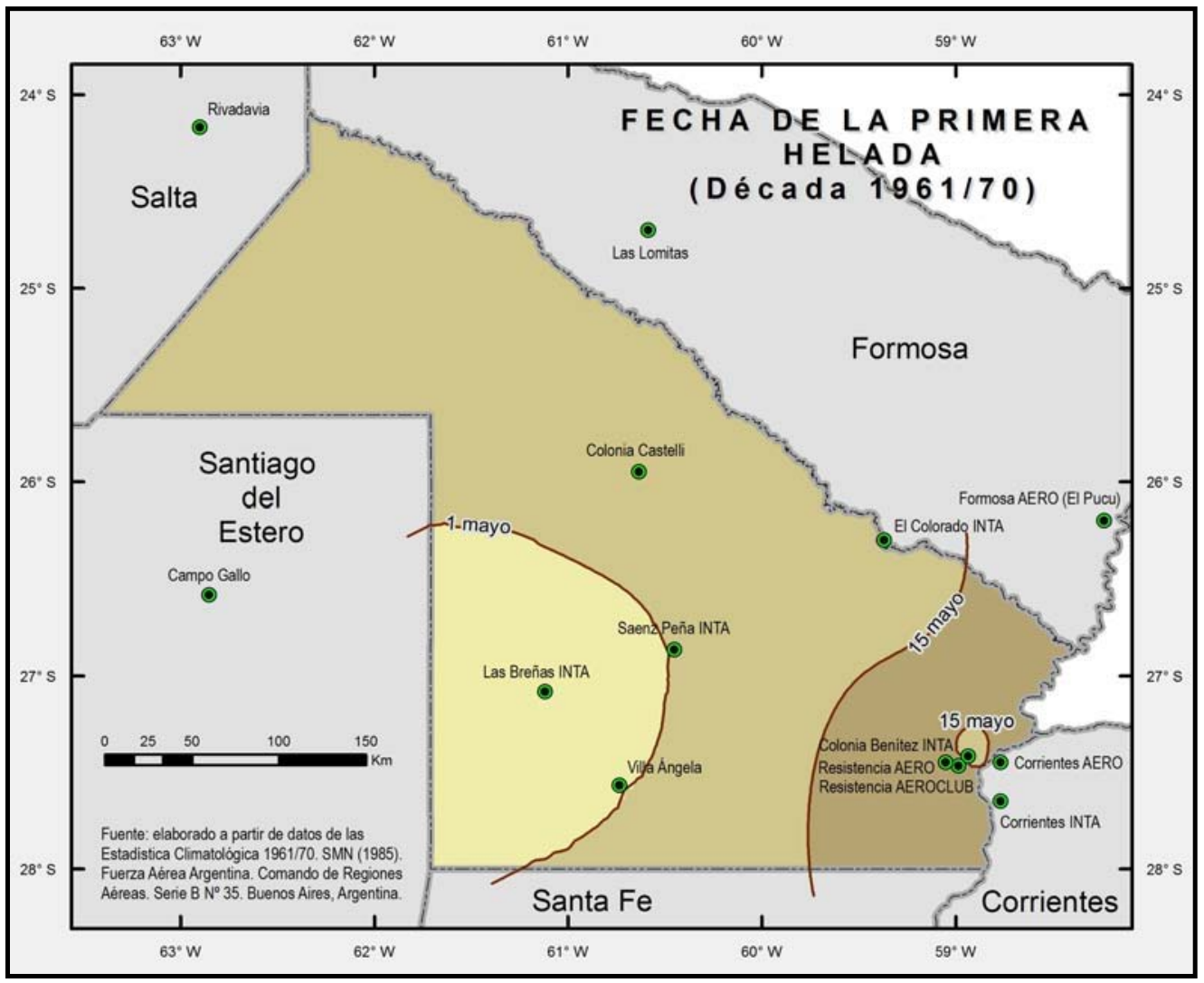

Publicado en formato digital: Prof. María de los Ángeles Martínez Jiménez y Prof. Patricia Perla Snaider. LA OCURRENCIA DE HELADAS Y SU INFLUENCIA EN LAS FASES DE LOS CULTIVOS EN LA PROVINCIA DEL CHACO ENTRE 1951 Y 2000. Revista Geográfica Digital. IGUNNE. Facultad de Humanidades. UNNE. Año 11. No 21. Enero - Junio 2014. ISSN 1668-5180. Resistencia, Chaco. 
Revista Geográfica Digital. IGUNNE. Facultad de Humanidades. UNNE. Año 11. № 21.

Enero - Junio 2014. ISSN 1668-5180. Resistencia, Chaco.

Figura 9: Fecha de la primera helada. Década 1971-1980.

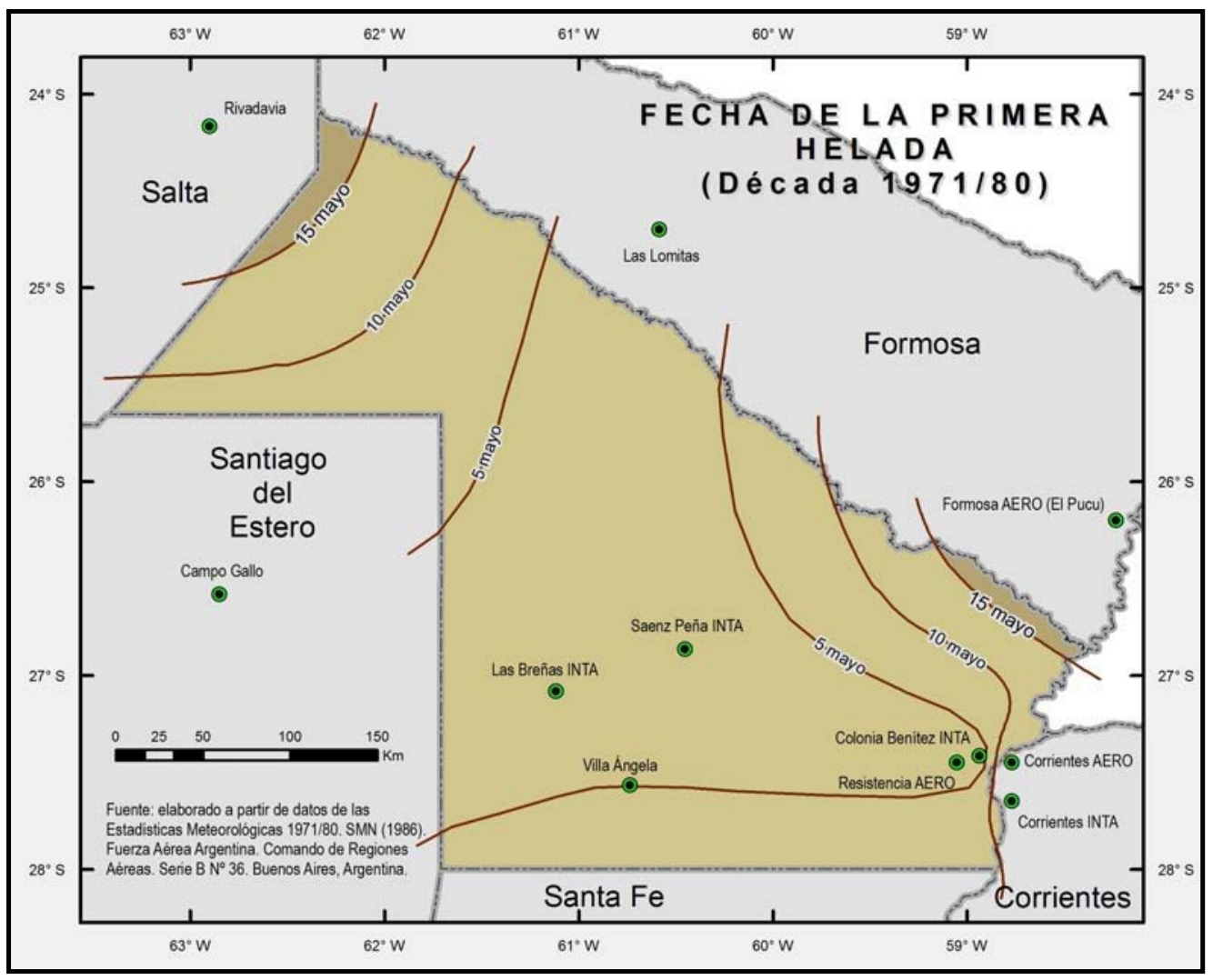

Figura 10: Fecha de la primera helada. Década 1981-1990.

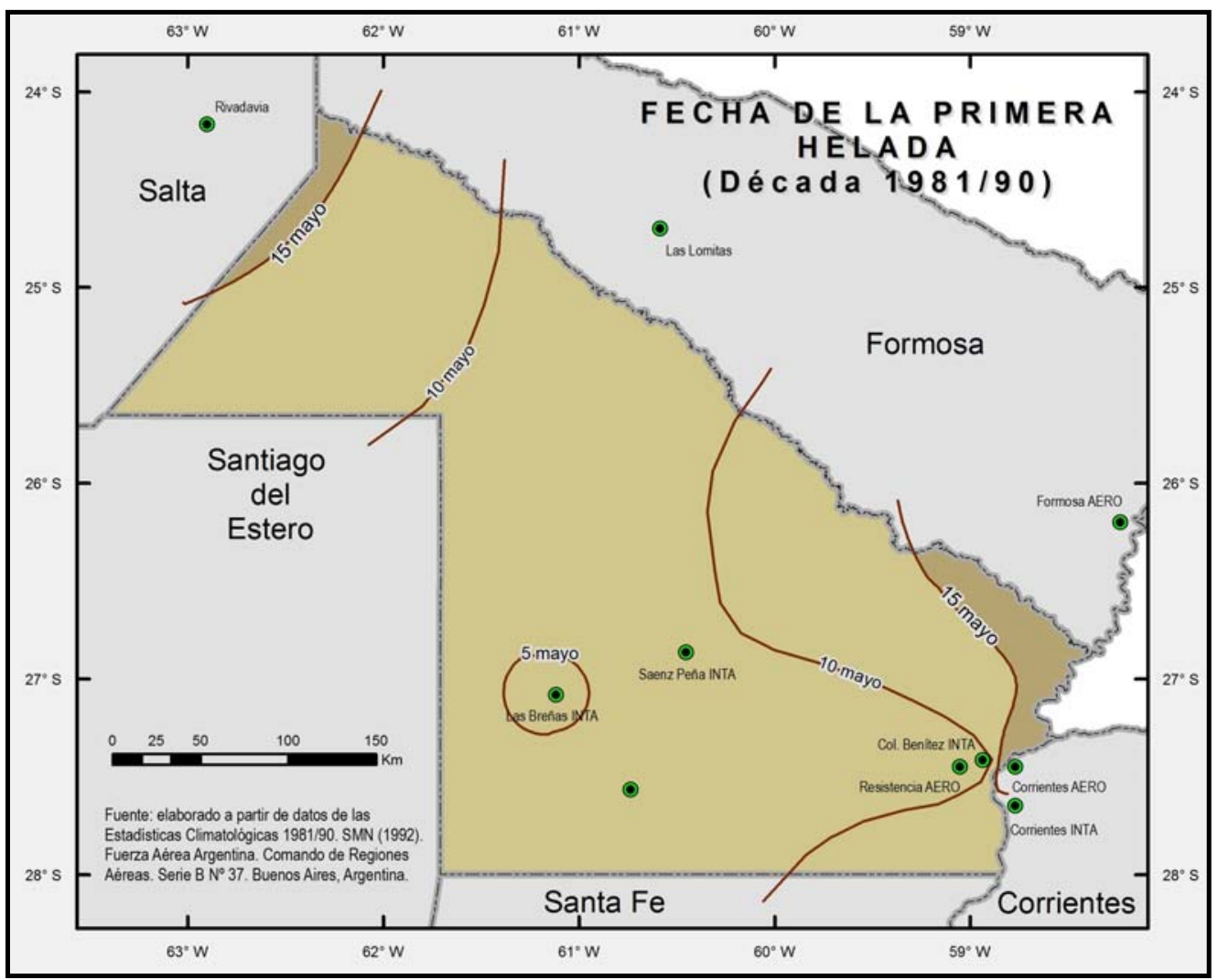

Publicado en formato digital: Prof. María de los Ángeles Martínez Jiménez y Prof. Patricia Perla Snaider. LA OCURRENCIA DE HELADAS Y SU INFLUENCIA EN LAS FASES DE LOS CULTIVOS EN LA PROVINCIA DEL CHACO ENTRE 1951 Y 2000. Revista Geográfica Digital. IGUNNE. Facultad de Humanidades. UNNE. Año 11. № 21. Enero - Junio 2014. ISSN 1668-5180. Resistencia, Chaco. 
Figura 11: Fecha de la primera helada. Década 1991-2000.

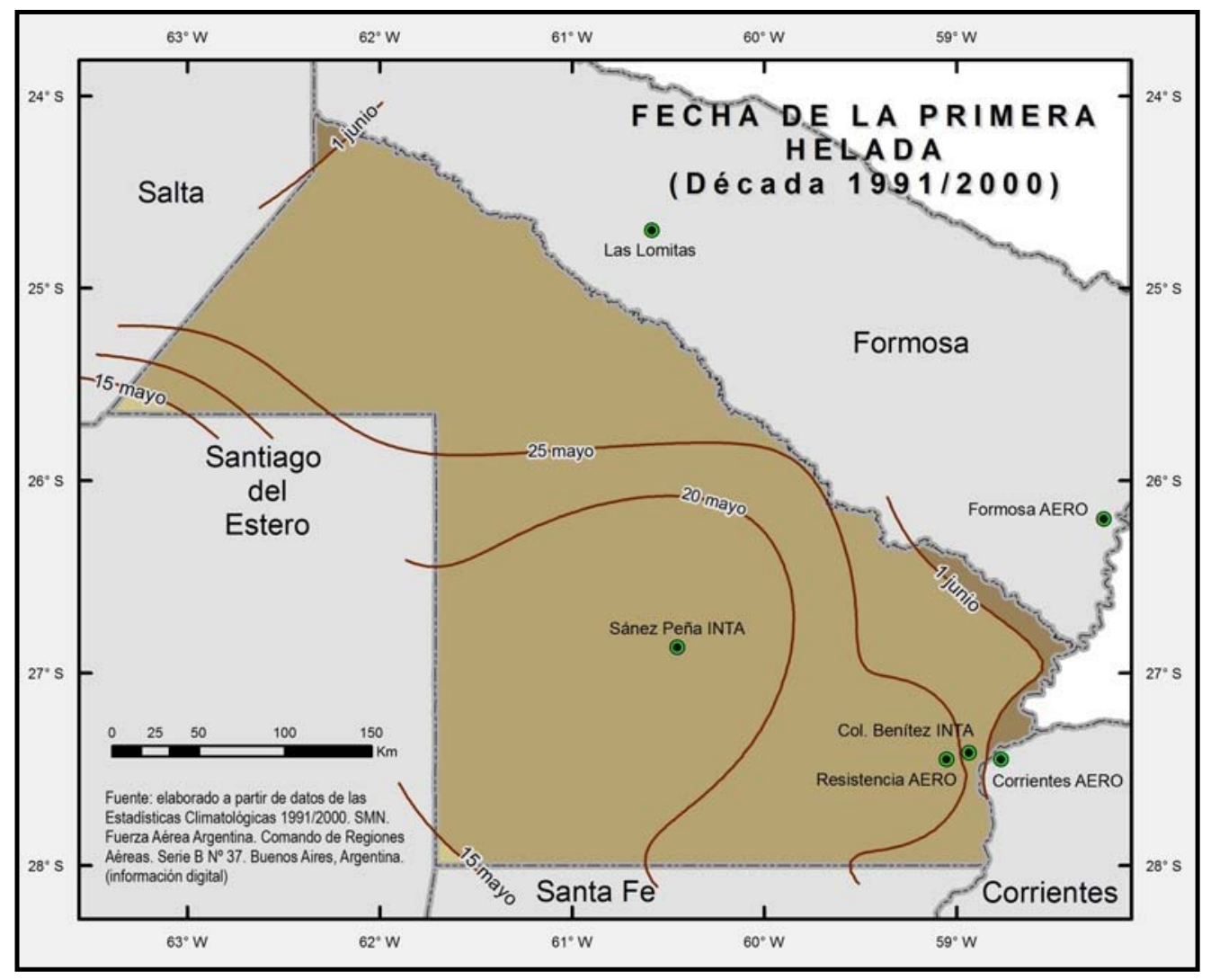

\section{Última helada}

La cartografía referente a las isocronas de las últimas heladas (figuras 12 a 16) demuestra, en prácticamente todas las décadas -con algunas variaciones- un retraso en la fecha de ocurrencia del fenómeno en sentido Este-Oeste. En la década de 1951-1960 se hace muy notoria esta variación. En el área oriental las últimas heladas se produjeron entre fines de julio y principios de agosto, mientras que en el área central y occidental de la provincia el período de heladas se extendió hasta la primera quincena de septiembre (ver figura 12).

Por su parte, en la década de 1961-1970 prácticamente en toda la superficie provincial las últimas heladas ocurrieron en el mes de septiembre, salvo en el área oriental en la que éstas se dieron a fines de agosto (ver figura 13). Para la década 1971-1980, si bien se observa la variación de las isocronas en sentido Este-Oeste como se mencionara anteriormente, se debe destacar que en el centro de la provincia se genera una isocrona cerrada con la fecha más tardía de la década correspondiente a heladas que se dieron a principios de octubre (ver figura 14).

En la figura 15, donde se representan las isocronas de la década 1981-1990, se observa que las últimas heladas se producen a fines de agosto y principio de septiembre en el oriente y en el Sur de la provincia; mientras que en el resto del Chaco el fenómeno se registra durante la segunda quincena de septiembre, y a principios de octubre sólo en la localidad de Sáenz Peña INTA. Por otra parte, en la década 1991-2000 se detecta que las últimas heladas ocurrieron entre finales del mes de agosto y principios de septiembre en el área oriental y un pequeño sector del Noroeste de la provincia, mientras que en la zona central y Sudoeste en la segunda quincena de septiembre (ver figura 16). 
Revista Geográfica Digital. IGUNNE. Facultad de Humanidades. UNNE. Año 11. № 21.

Enero - Junio 2014. ISSN 1668-5180. Resistencia, Chaco.

Figura 12: Fecha de la última helada. Década 1951-1960.

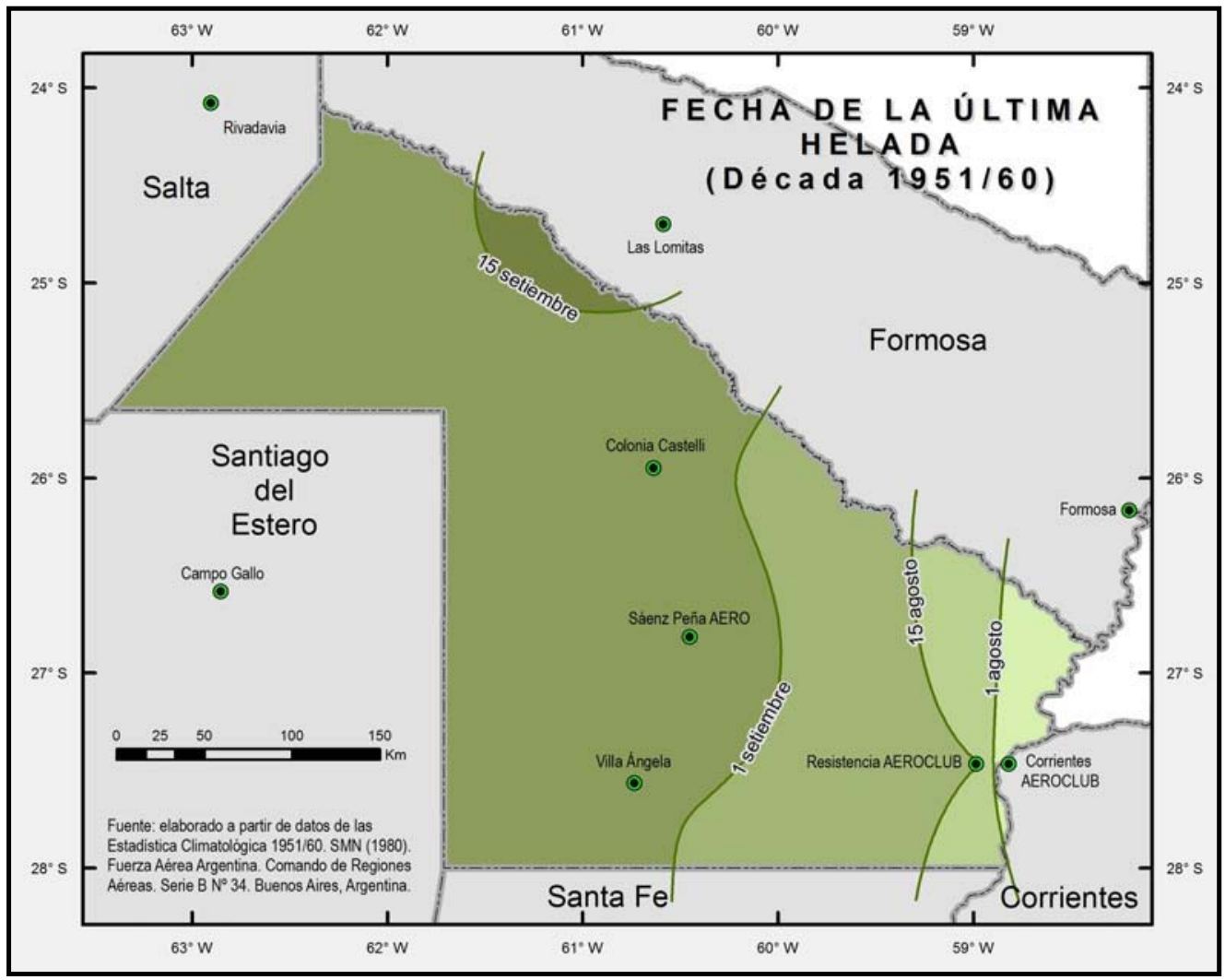

Figura 13: Fecha de la última helada. Década 1961-1970.

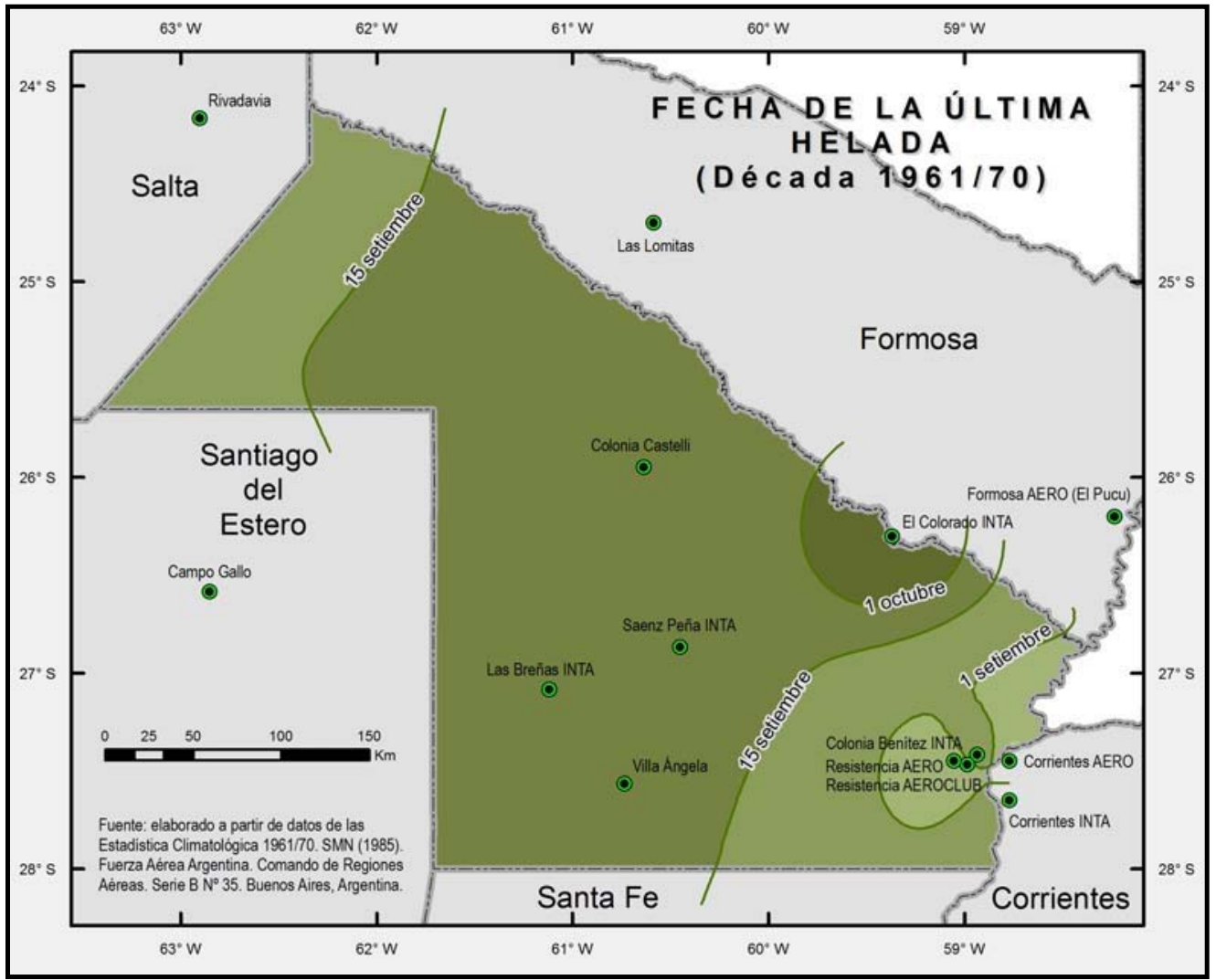

Publicado en formato digital: Prof. María de los Ángeles Martínez Jiménez y Prof. Patricia Perla Snaider. LA OCURRENCIA DE HELADAS Y SU INFLUENCIA EN LAS FASES DE LOS CULTIVOS EN LA PROVINCIA DEL CHACO ENTRE 1951 Y 2000. Revista Geográfica Digital. IGUNNE. Facultad de Humanidades. UNNE. Año 11. № 21. Enero - Junio 2014. ISSN 1668-5180. Resistencia, Chaco. 
Revista Geográfica Digital. IGUNNE. Facultad de Humanidades. UNNE. Año 11. № 21.

Enero - Junio 2014. ISSN 1668-5180. Resistencia, Chaco.

Figura 14: Fecha de la última helada. Década 1971-1980.

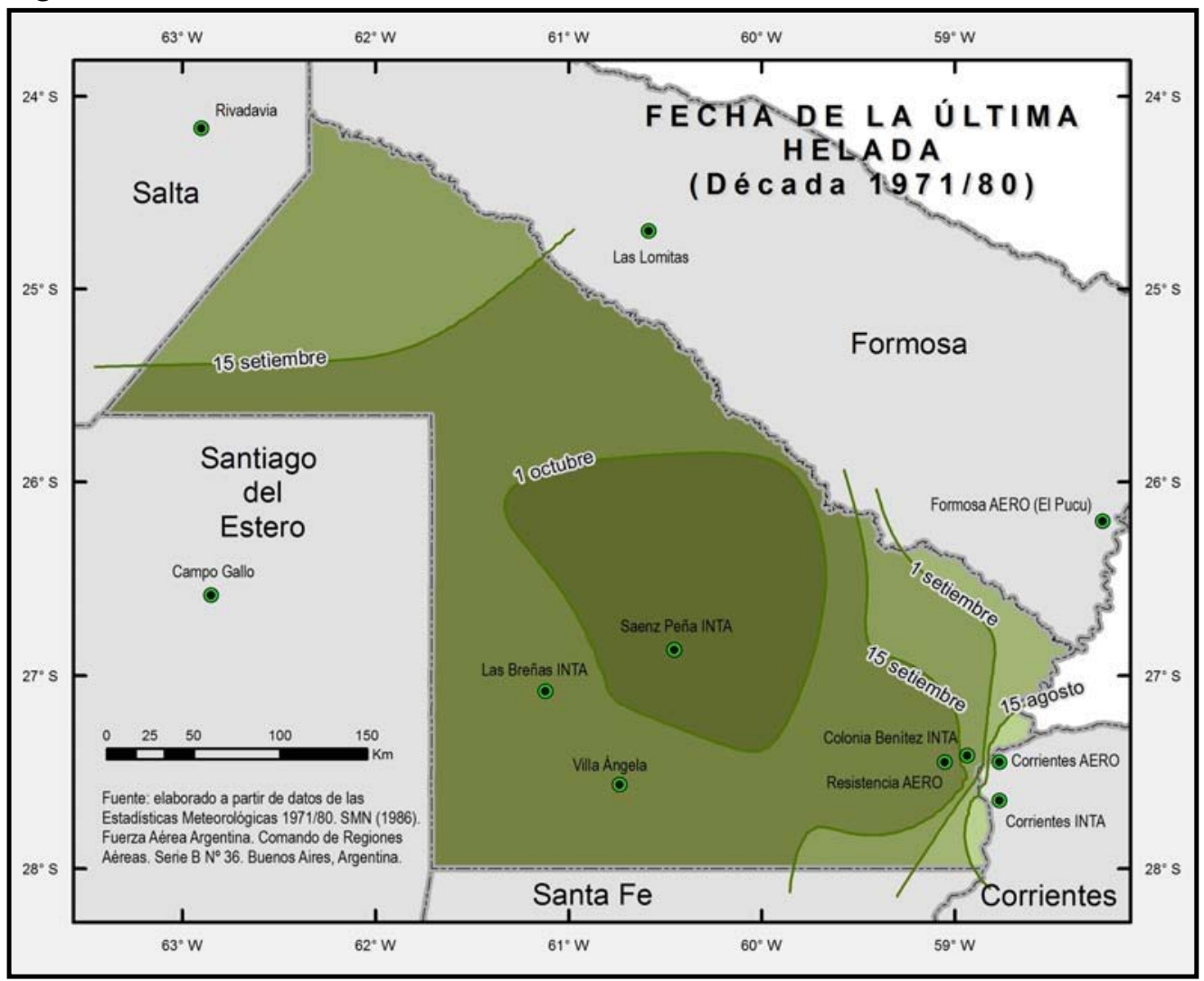

Figura 15: Fecha de la última helada. Década 1981-1990.

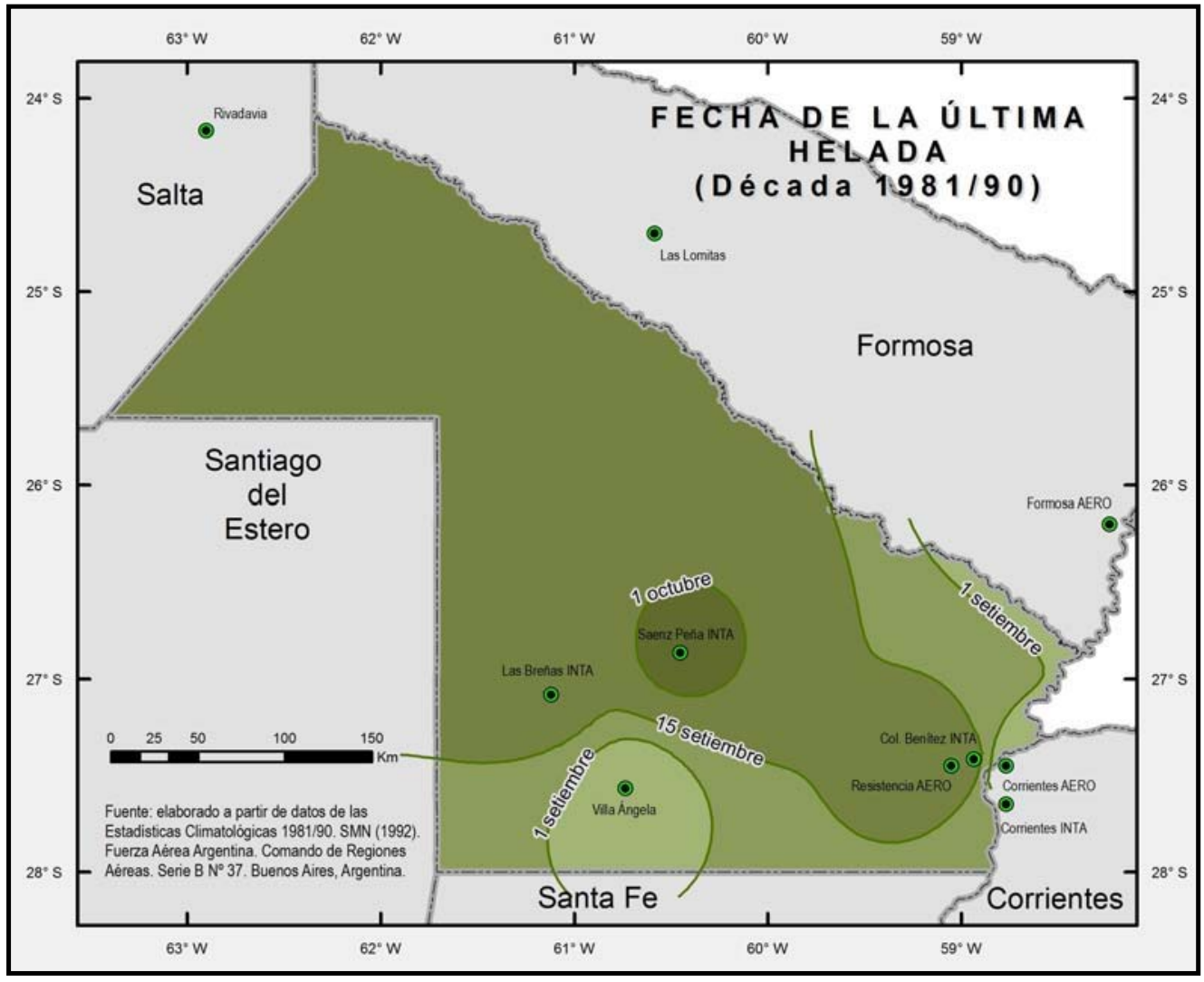

Publicado en formato digital: Prof. María de los Ángeles Martínez Jiménez y Prof. Patricia Perla Snaider. LA OCURRENCIA DE HELADAS Y SU INFLUENCIA EN LAS FASES DE LOS CULTIVOS EN LA PROVINCIA DEL CHACO ENTRE 1951 Y 2000. Revista Geográfica Digital. IGUNNE. Facultad de Humanidades. UNNE. Año 11. No 21. Enero - Junio 2014. ISSN 1668-5180. Resistencia, Chaco. 
Figura 16: Fecha de la última helada. Década 1991-2000.

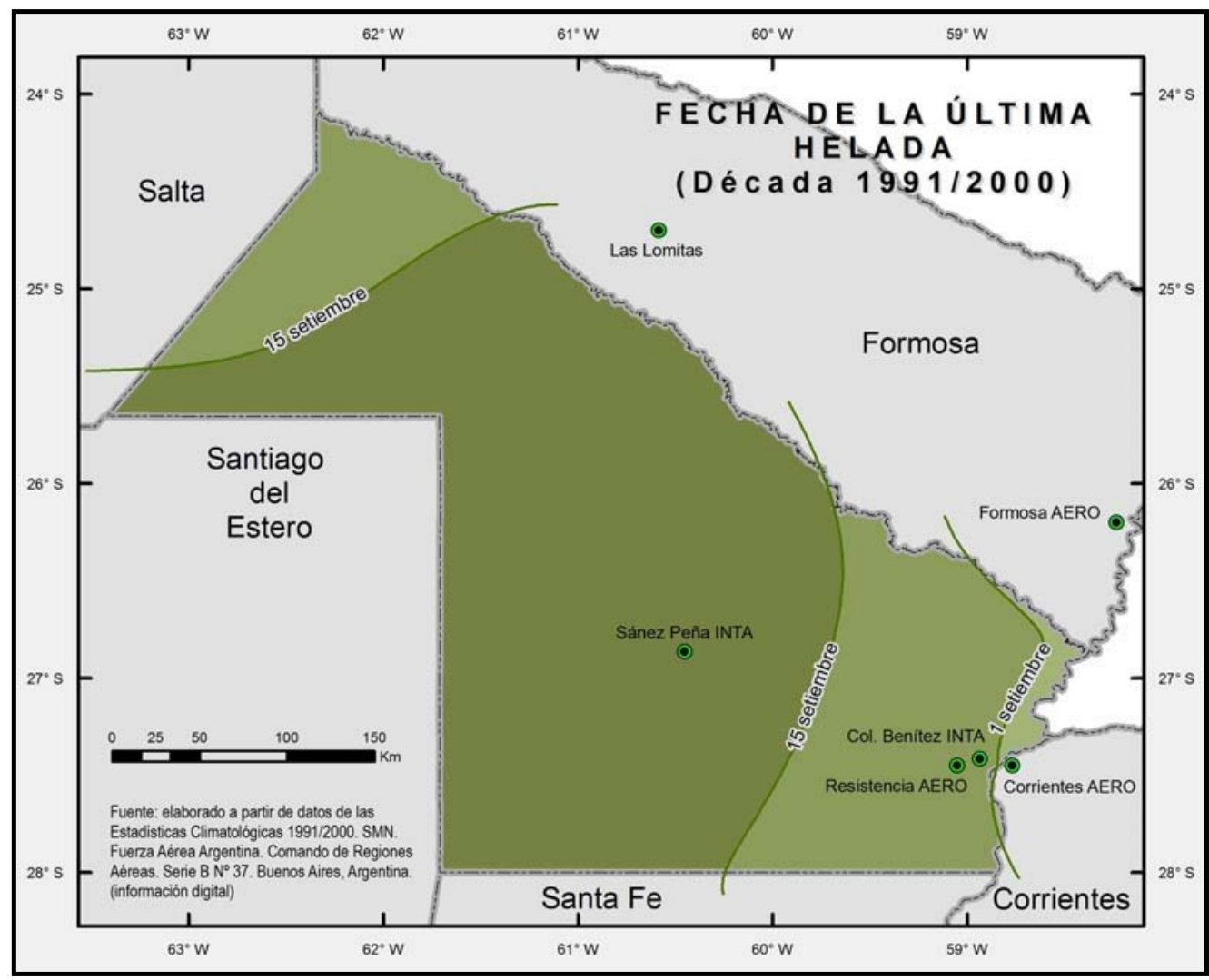

Tabla 5.a: Fechas de heladas extremas registradas en el Chaco en cada década estudiada, con su correspondiente localización dentro de la provincia.

\begin{tabular}{|c|c|c|c|c|c|c|}
\hline \multirow{2}{*}{ DÉCADA } & \multicolumn{2}{|c|}{ PRIMERA HELADA } & \multicolumn{2}{c|}{ ÚLTIMA HELADA } & \multicolumn{2}{c|}{$\begin{array}{c}\text { DURACIÓN } \\
\text { (días al año) }\end{array}$} \\
\cline { 2 - 6 } & Fecha & Lugar & Fecha & \multicolumn{2}{c|}{ Lugar } & \multicolumn{2}{c|}{ as } \\
\hline $\mathbf{1 9 5 1 - 1 9 6 0}$ & $20 \mathrm{abr}$ & Centro/ Norte & $11 \mathrm{sep}$ & Centro & 144 & $39.5 \%$ \\
\hline $\mathbf{1 9 6 1 - 1 9 7 0}$ & $21 \mathrm{abr}$ & Centro/ Sudoeste & $25 \mathrm{sep}$ & Centro/ Sudoeste & 157 & $43 \%$ \\
\hline $\mathbf{1 9 7 1 - 1 9 8 0}$ & $1 \mathrm{may}$ & Centro/ Este & $30 \mathrm{sep}$ & Centro/ Sudoeste & 152 & $41.6 \%$ \\
\hline $\mathbf{1 9 8 1 - 1 9 9 0}$ & $4 \mathrm{may}$ & Centro & 2 oct & Centro & 151 & $41.4 \%$ \\
\hline $\mathbf{1 9 9 1 - 2 0 0 0}$ & 19 may & Centro & $21 \mathrm{sep}$ & Centro & 125 & $34.2 \%$ \\
\hline
\end{tabular}

Tabla 5.b: Duración del período de heladas. Heladas tempranas y tardías.

\begin{tabular}{|c|c|c|c|c|c|c|c|}
\hline DÉCADA & Abril & Mayo & Junio & Julio & Agosto & Seti & Octubre \\
\hline 1951-1960 & - & & & & & - & \\
\hline 1961-1970 & & & & & & & \\
\hline 1971-1980 & & & & & & & \\
\hline $1981-1990$ & & & & & & & \\
\hline 1991-2000 & & & & & & & \\
\hline
\end{tabular}

Fuente: Elaborado a partir de los datos publicados por las estadísticas Climatológicas del S.M.N. (décadas 195160, 1961-70, 1971-80, 1981-90 y 1991-2000). 
Revista Geográfica Digital. IGUNNE. Facultad de Humanidades. UNNE. Año 11. № 21. Enero - Junio 2014. ISSN 1668-5180. Resistencia, Chaco.

A modo de síntesis, en la tabla $\mathbf{5}$.a se presentan las fechas en que se produjeron las primeras y últimas heladas dentro de la provincia del Chaco en cada una de las décadas analizadas; junto con la localización aproximada de la/s estación/nes meteorológicas donde se hayan registrado la primer y última helada en el espacio provincial. En la última columna se muestra la duración del período de heladas, es decir, el número de días al año entre la primera (helada temprana) y la última helada (helada tardía); dicho período fue representado en la tabla 5.b. Se obtuvieron las siguientes características:

- Teniendo en cuenta los 50 años de estudio, las heladas tempranas en la Provincia del Chaco se registran entre la segunda quincena del mes de abril y la segunda quincena de mayo.

- Las heladas tempranas cada vez se registraban con mayor retraso conforme se avanza en las décadas; es decir, en la primer década fue observada el 20 de abril, mientras que en la última década el 19 de mayo, un mes después.

- Teniendo en cuenta los 50 años de estudio, las heladas tardías en la Provincia del Chaco se registran entre la primera quincena del mes de septiembre y los primeros días de octubre.

- En las heladas tardías también se advierte un retraso conforme se avanza en las décadas (en la primer década la última helada fue el 11 de septiembre mientras que en la cuarta década fue el 2 de octubre -21 días después-), salvo en la última cuya fecha se corresponde con el 21 de septiembre.

- La duración del período de heladas durante los 50 años analizados, es de entre 125 y 157 días al año (34,2\% y $43 \%$ del año con heladas, respectivamente).

- Si se comparan cada una de las décadas analizadas, en general el período de heladas cada vez comienza más tarde, pero también termina más tarde.

- En la última década - 1991/2000 - el período de heladas es más corto (no llega al 35\% de los días del año) en comparación con el resto de las décadas (entre el $40 \%$ y $43 \%$ de de los días del año con heladas).

\section{Influencia de las heladas en las fases fenológicas de los cultivos}

Es necesario conocer los momentos en los que se originan las distintas fases fenológicas del ciclo biológico de cada cultivo, desde la siembra hasta la cosecha, para determinar cuáles de éstas fases son susceptibles de verse afectadas por las heladas, puesto que, como mencionan De Fina y Ravelo (1973: 193), "el daño que produce sobre el cultivo de una determinada variedad agrícola una helada de intensidad y duración, también determinadas, depende principalmente del momento del ciclo vegetativo en el cual ésta ocurre".

La vida de cualquiera de las plantas se divide en dos estadios: el vegetativo y el reproductivo. El primero comienza con la siembra -que no se considera como una fase dentro del ciclo, sino como una práctica- en la cual la semilla es colocada en la superficie del suelo. Días posteriores, se produce la germinación-emergencia, que es aquella etapa en que la semilla en estado de vida latente entra en actividad y origina una nueva planta que emerge hacia la superficie -en el caso de las plantas dicotiledóneas como el girasol y el algodón, se considera que esta fase ocurre cuando emergen los cotiledones-. Para que se produzca la emergencia deben darse ciertas condiciones favorables que dependen de cada especie. Además, en esta etapa comienzan a formarse las hojas verdaderas de la planta cuya cantidad también depende del cultivo que se trate.

Publicado en formato digital: Prof. María de los Ángeles Martínez Jiménez y Prof. Patricia Perla Snaider. LA OCURRENCIA DE HELADAS Y SU INFLUENCIA EN LAS FASES DE LOS CULTIVOS EN LA PROVINCIA DEL CHACO ENTRE 1951 Y 2000. Revista Geográfica Digital. IGUNNE. Facultad de Humanidades. UNNE. Año 11. No 21. Enero - Junio 2014. ISSN 1668-5180. Resistencia, Chaco. 
Revista Geográfica Digital. IGUNNE. Facultad de Humanidades. UNNE. Año 11. № 21. Enero - Junio 2014. ISSN 1668-5180. Resistencia, Chaco.

La etapa reproductiva se inicia una vez terminada la vegetativa, con la emisión del polen y con la aparición, evolución y transformación de la inflorescencia y su posterior reproducción a lo largo de varias fases, de lo que se forman los granos que se van llenando de material de distinta consistencia. Este proceso culmina con la madurez de los granos, o sea, cuando la mayoría de ellos ha terminado de formarse, para posteriormente producirse la cosecha de los mismos -al igual que la siembra, se la considera una práctica cultural-.

Teniendo en cuenta el período del año en el que se producen heladas, es decir, las fechas extremas en las que comienza y finaliza este fenómeno meteorológico y las fechas en las que se inician las fases del ciclo ontogénico de cada cultivo chaqueño, se pudo determinar cuáles de éstas últimas coinciden con la ocurrencia del hidrometeoro en estudio, datos que fueron consignados en la Tabla 3: Fechas de Fenología de los cultivos del Chaco y período con heladas. En ésta se relacionaron los datos de las fechas de inicio de cada fase con la de primera y última helada y seguidamente, como fruto de un análisis posterior, se pudo determinar cuáles de estas fases son las más susceptibles de ser afectadas por las heladas.

Según Castillo y Castelvi Sentis (1996) el girasol es, de todos los cultivos analizados, el más resistente a este tipo de adversidades meteorológicas. Por ello puede sembrarse sin problemas a principios de primavera, por ser relativamente resistente a la helada y por su baja temperatura de germinación; sin embargo, si la helada se produce en su etapa reproductiva, éstas dañan y destruyen las flores. Es decir que su fase más crítica comienza a partir de la iniciación floral abarcando todo el proceso de floración.

Las heladas tardías producidas a fines de septiembre afectaron en todas las décadas el subperíodo (tiempo transcurrido entre dos fases) que se extiende entre la iniciación floral y el botón floral (en el inicio de etapa reproductiva); sin embargo, las heladas más tardías del mes de octubre que se registraron desde la década 1961-70 hasta la de 1991-2000, principalmente en la zona central de la provincia afectaron aún más, ya que se dieron en el subperíodo que se extiende entre el botón floral y la floración, lo que se observa en la tabla 6.a.

En el caso del girasol (de siembra tardía), por su posterior fecha de siembra que el anterior, las heladas producidas a finales de septiembre y principios de octubre (heladas tardías) no produjeron daños en la planta, ya que se dieron en períodos resistentes a las mismas, es decir, en la etapa vegetativa, y no llegaron a afectar la etapa reproductiva.

El momento más crítico y vulnerable para los otros cultivos es la primera de sus fases, es decir la fase de germinación-emergencia. En los cultivos anuales, principalmente en primavera, comienza una gran sensibilidad a los descensos bruscos de temperatura y, por ende, una gran susceptibilidad a las heladas. Tal es así que, una helada que se produzca en primavera (helada tardía) afectaría enormemente a una planta pudiendo disminuir su rendimiento, e incluso provocar la muerte de la misma (de sus tejidos vegetales) ya que la primera fase del ciclo ontogénico es una de las más críticas en torno a la temperatura, considerando que en esta época dichos cultivos se encuentran recién nacidos o con poca vida activa y son muy sensibles al frío. Por ejemplo, el cultivo del maíz no es resistente a las heladas, ya que éstas dañan a la planta en todas las fases de desarrollo, y es por ello que requiere de por lo menos una estación libre de heladas de aproximadamente cuatro meses y medio. (CASTILLO y CASTELVI SENTIS, 1996).

Por su parte, el maíz de primera se vio afectado, producida la emergencia de la plántula, por las heladas tardías durante las décadas de 1961-70 a 1991-2000, principalmente en la zona central de la provincia, tal como se consigna en la Tabla 6.b. 
Revista Geográfica Digital. IGUNNE. Facultad de Humanidades. UNNE. Año 11. No 21. Enero - Junio 2014. ISSN 1668-5180. Resistencia, Chaco.

Tabla 6.a: Fechas extremas de heladas y fases del cultivo

\begin{tabular}{|l|l|l|l|l|l|l|l|l|l|l|l|l|}
\hline GIRASOL (Siembra Temprana) & E & F & M & A & M & J & J & A & S & O & N & D \\
\hline Fechas extremas (década 51-60) & & & & 20 & & & & & 11 & & & \\
\hline Fechas extremas (década 61-70) & & & & 21 & & & & & 25 & & & \\
\hline Fechas extremas (década 71-80) & & & & & 1 & & & & & 7 & & \\
\hline Fechas extremas (década 81-90) & & & & & 4 & & & & & 2 & & \\
\hline Fechas extremas (década 91-00) & & & & & 19 & & & & 21 & & & \\
\hline Siembra & & & & & & & & 1 & & & & \\
\hline Emergencia & & & & & & & & 8 & & & & \\
\hline Iniciación Floral & & & & & & & & & $\mathbf{1 9}$ & & & \\
\hline Botón Floral & & & & & & & & & & $\mathbf{1 2}$ & & \\
\hline Floración & & & & & & & & & & 22 & & \\
\hline Fin de Floración & & & & & & & & & & & & 9 \\
\hline Madurez Fisiológica & & & & & & & & & & & 24 \\
\hline Cosecha
\end{tabular}

\begin{tabular}{|c|c|}
\hline Referencias & \\
\hline 1 & Fechas de inicio de fase del ciclo ontogénico \\
\hline 11 & Fechas extremas de heladas \\
\hline & Fases y subperíodos afectado por heladas \\
\hline
\end{tabular}

Tabla 6.b: Fechas extremas de heladas y fases del cultivo

\begin{tabular}{|l|l|l|l|l|l|l|l|l|l|l|l|l|}
\hline MAíz de Primera & E & F & M & A & M & J & J & A & S & O & N & D \\
\hline $\begin{array}{l}\text { Fechas extremas } \\
\text { (década 51-60) }\end{array}$ & & & & 20 & & & & & 11 & & & \\
\hline $\begin{array}{l}\text { Fechas extremas } \\
\text { (década 61-70) }\end{array}$ & & & & & 1 & & & & & 7 & & \\
\hline $\begin{array}{l}\text { Fechas extremas } \\
\text { (década 71-80) }\end{array}$ & & & & & 4 & & & & & 2 & & \\
\hline $\begin{array}{l}\text { Fechas extremas } \\
\text { (década 81-90) }\end{array}$ & & & & & 19 & & & & 21 & & & \\
\hline $\begin{array}{l}\text { Fechas extremas } \\
\text { (década 91-00) }\end{array}$ & & & & & & & & & $\mathbf{1 0}$ & & & \\
\hline Siembra & & & & & & & & & & $\mathbf{2 0}$ & & \\
\hline Emergencia & & & & & & & & & & & 20 & \\
\hline Fin de fase juvenil & 23 & & & & & & & & & & & \\
\hline Floración & 28 & & & & & & & & & & & \\
\hline Inicio de llenado de granos & & & & & & & & & & & & \\
\hline Madurez Fisiológica
\end{tabular}

Fuente: Elaborado a partir de los datos de las Estadísticas Climatológicas del S.M.N (Década 1951-60, 1961-70, 1971-80, 1981-90 y 1991-2000) y de la Oficina de Riesgos Agropecuarios.

El sorgo se comporta de manera similar al maíz, ya que no es resistente a la helada e incluso requiere más calor que éste. Según Castillo y Castelvi Sentis (1996: 334) "las semillas comienzan el 
Revista Geográfica Digital. IGUNNE. Facultad de Humanidades. UNNE. Año 11. № 21.

Enero - Junio 2014. ISSN 1668-5180. Resistencia, Chaco.

proceso de germinación a unos $10{ }^{\circ} \mathrm{C}$, pero las temperaturas bajas en la época de siembra generan una mala germinación".

Al igual que el maíz y el sorgo, el algodón no es resistente a las heladas ya que éstas lo afectan en todas sus fases de desarrollo y requiere de altas temperaturas (superiores a $10^{\circ} \mathrm{C}$ ) para germinar, ya que, como explica Castillo y Castelvi Sentis (1996) el desarrollo de las plántulas se ve interrumpido si la temperatura son bajas. Por sus fechas de siembra, tanto el algodón de siembra temprana como tardía no se vieron afectados por las heladas tempranas ni tardías en ninguna de las décadas estudiadas.

\section{CONCLUSIONES}

La agricultura se encuentra altamente influenciada por la ocurrencia de eventos climáticos adversos que pueden afectar el rendimiento de los cultivos y generar pérdidas en dicha actividad. Es por ello que, como lo publica el Servicio Meteorológico Nacional "es necesario el estudio agroclimático porque la elección de las especies y variedades a cultivar, de los lugares de implantación y de las épocas de posible desarrollo, deben ser hechos con el conocimiento de todos los peligros que involucran las heladas..." (FUERZA AÉREA ARGENTINA, 1985: 16).

En torno a ello, este trabajo ha permitido determinar la influencia que tiene este hidrometeoro en los principales cultivos de la provincia del Chaco en los últimos cincuenta años y abordar algunas conclusiones parciales al respecto:

- En la región oriental la frecuencia anual es menor que en el área occidental y el incremento de ocurrencia del hidrometeoro se hace prácticamente en sentido longitudinal.

- El período en que se registran heladas en la provincia, es decir, las fechas extremas que representan la primera y última helada, varían entre fines de abril y principios de octubre.

- Las dos primeras décadas -fundamentalmente la primera- se caracterizan por una amplia variación del trazado de las isócronas que representan las heladas tempranas, es decir, el momento en que se produce la primera helada. Dichas isolíneas presentan una disposición prácticamente longitudinal e indican que la fecha de la primera helada varía en el espacio provincial desde fines de abril en la zona occidental hasta principios de julio en la oriental (primera década) y desde fines de abril hasta mediados de mayo (segunda década). Por el contrario, a partir de la década de 1971/80 y hasta 1991/2000, las fechas de la primera helada que se registraron prácticamente en toda la provincia fueron en el mes de mayo.

- Los cultivos que se ven afectados por heladas primaverales son aquellos que se siembran en forma temprana. Las heladas tardías (se producen en primavera) son las que, con mayor frecuencia, perjudican a las plantas cultivadas, ya que coinciden con la época o fase de desarrollo más susceptible en torno a la temperatura que requieren para completar su desarrollo.

- El girasol, que se siembra en forma temprana, se vio afectado por estas heladas en el comienzo de su etapa reproductiva y en la fase de iniciación floral durante todo el período de análisis -cinco décadas- en el centro y Sudoeste de la provincia.

- El maíz de primera -también sembrado en forma temprana- por su fecha de siembra y por ser un cultivo muy poco resistente a las heladas fue afectado en su fase de germinación-emergencia desde la década 1961-70 hasta la década 1991-2000 en las mismas regiones que el cultivo anterior.

Publicado en formato digital: Prof. María de los Ángeles Martínez Jiménez y Prof. Patricia Perla Snaider. LA 
Revista Geográfica Digital. IGUNNE. Facultad de Humanidades. UNNE. Año 11. № 21.

Enero - Junio 2014. ISSN 1668-5180. Resistencia, Chaco.

- En cuanto a las fechas de ocurrencia de las últimas heladas se advierte una variación del trazado de las isócronas en sentido longitudinal, al igual que la disposición de las isolíneas que representan las fechas en que se producen las primeras heladas. Además en el área central siempre se encuentran las fechas más tardías, en oposición a la zona oriental en la que el período de ocurrencia finaliza más temprano.

- Las heladas otoñales prácticamente no han demostrado influencia negativa en los cultivos de la provincia.

\section{REFERENCIAS CITADAS}

BRUNIARD, Enrique (Dir.); PÉREZ, María Emilia; GONZÁLEZ, Carlos y A. BIANCONI (2001): "EI clima de la región algodonera Argentina". Programa integral algodonero (PROINTAL), Ministerio de la Producción de la provincia del Chaco, acuerdo Gobierno de la Provincia del Chaco - UNNE. Resistencia. En: httpllwww.unne.edu.arlWEBIpublicaciones/climatologia.

BURGOS, Juan (1963): Las heladas en la Argentina. Buenos Aires, INTA. 345 pp.

CASTILLO, Elías Francisco y CASTELVI SENTIS, Francesc (Coord) (1996): Agrometeorología. Madrid, España. 517 pp.

DE FINA, Armando y RAVELO, Andrés (1973): Climatología y fenología agrícolas. Buenos Aires, Argentina. $281 \mathrm{pp}$.

FUERZA AÉREA ARGENTINA (1985): "Heladas". En: Boletín Informativo $N^{\circ}$ 17. Servicio Meteorológico Nacional, Comando de Regiones Aéreas. Capital. 28 pp.

\section{BIBLIOGRAFIA}

BRUNIARD, Enrique (1981): El clima de las planicies del norte Argentino (Ensayo metodológico de geografía de los climas). Facultad de Humanidades, UNNE, Resistencia.

BRUNIARD, Enrique (Dir.) et al. (1987): "Atlas Geográfico de la Provincia del Chaco". Tomo I: El Medio Natural. En: Revista Geográfica No 5. Instituto de Geografía, Facultad de Humanidades, Universidad Nacional del Nordeste. Resistencia, Chaco. República Argentina.

BRUNIARD, Enrique (Dir.) et al. (1997): "Atlas Geográfico de la provincia de Corrientes. Tomo I: El Medio Natural". En: Revista Geográfica $N^{0}$ 8. Instituto de Geografía, Facultad de Humanidades. Universidad Nacional del Nordeste. Resistencia, Chaco. República Argentina.

BRUNIARD, Enrique (Dir.); PÉREZ, María Emilia; GONZÁLEZ, Carlos y A. BIANCONI (Colab.). (2001): "El clima de la región algodonera Argentina". Programa integral algodonero (PROINTAL) Ministerio de la Producción de la provincia del Chaco, acuerdo Gobierno de la Provincia del Chaco - UNNE. Resistencia. En: httpllwww.unne.edu.arlWEBlpublicacioneslclimatologia

BURGOS, Juan (1963): Las heladas en la Argentina. Buenos Aires, INTA.

CASTILLO, Elías Francisco y CASTELVI SENTIS, Francesc (Coord) (1996): Agrometeorología. Madrid, España.

DAMARIO E. A., A. J. PASCALE, S. PEREZ S. MAIO y R. O. RODRÍGUEZ. (1996): Cartas climáticas 1961-1990 de primeras y últimas heladas en la Argentina. Rev. Facultad de Agronomía, 16 (3): 253-263.

DE FINA, Armando y RAVELO, Andrés. (1973): Climatología y fenología agrícolas. Buenos Aires, Argentina.

DE MARTONNE, Emmanuel (1964): Tratado de Geografía Física. Barcelona, Juventud, T. I.

Publicado en formato digital: Prof. María de los Ángeles Martínez Jiménez y Prof. Patricia Perla Snaider. LA OCURRENCIA DE HELADAS Y SU INFLUENCIA EN LAS FASES DE LOS CULTIVOS EN LA PROVINCIA DEL CHACO ENTRE 1951 Y 2000. Revista Geográfica Digital. IGUNNE. Facultad de Humanidades. UNNE. Año 11. No 21. Enero - Junio 2014. ISSN 1668-5180. Resistencia, Chaco. 
Revista Geográfica Digital. IGUNNE. Facultad de Humanidades. UNNE. Año 11. № 21. Enero - Junio 2014. ISSN 1668-5180. Resistencia, Chaco.

DOMINGUEZ BASCÓN, Pedro (1986): Las heladas en la Provincia de Córdoba. En: Estudios Geográficos, número XLVII, 182-183, CSIC, Madrid, España. Febrero -mayo de 1986. pp. 193-210.

FUERZA AÉREA ARGENTINA (1985): Heladas. En: Boletín Informativo $N^{\circ}$ 17. Servicio Meteorológico Nacional, Comando de Regiones Aéreas. Capital. 28 pp.

MANOILLOF, Raúl, PEREZ, María E. y REY, Walter (Dir.) y equipo (2009): “Atlas Geográfico de la provincia del Chaco. Tomo III: Las Actividades Primarias". En: Revista Geográfica No 16. Instituto de Geografía, Facultad de Humanidades. Universidad Nacional del Nordeste. Resistencia, Chaco. República Argentina.

MILLER, Austin. (1975): Climatología. Barcelona, Omega.

PICCHI C.G. y BARRETT H. G. (1967): "Efecto de heladas intensas sobre las especies de "Pinus" en Castellar". En: Revista IDIA N²0. Suplemento Forestal N4. INTA. Buenos Aires, Argentina.

STRAHLER, Arthur y STRAHLER, Alan (1997): Geografía Física. 3a edición. Barcelona, ed. Omega.

STRASCHNOY, J. V.; DI BELLA, C. M.; JAIMES, F. R.; ORICCHIO, P. A. y REBELLA, C. M. (2006): Caracterización espacial del estrés hídrico y de las heladas en la Región Pampeana a partir de información satelital y complementaria. RIA, 35 (2): 117-141, INTA, Argentina.

REYNA TRUJILLO, Teresa (1989): "Contribución ecoclimática para el desarrollo frutícola de Michoacán, un parámetro: heladas" Boletín del Instituto de Geografía $N^{\circ}$ 20. Universidad nacional Autónoma de México, México.

\section{FUENTES ESTADÍSTICAS}

SERVICIO METEOROLÓGICO NACIONAL (1980): Estadística Climatológica 1951/60. Fuerza Aérea Argentina. Comando de Regiones Aéreas. Serie B No 34. Buenos Aires, Argentina.

SERVICIO METEOROLÓGICO NACIONAL (1985): Estadística Climatológica 1961/70. Fuerza Aérea Argentina. Comando de Regiones Aéreas. Serie B No 35. Buenos Aires, Argentina.

SERVICIO METEOROLÓGICO NACIONAL (1986): Estadísticas Meteorológicas 1971/80. Fuerza Aérea Argentina. Comando de Regiones Aéreas. Serie B Nº 36. Buenos Aires, Argentina.

SERVICIO METEOROLÓGICO NACIONAL (1992): Estadísticas Climatológicas 1981/90. Fuerza Aérea Argentina. Comando de Regiones Aéreas. Serie B No 37. Buenos Aires, Argentina.

SERVICIO METEOROLÓGICO NACIONAL. Estadísticas Climatológicas 1991/2000. Fuerza Aérea Argentina. Comando de Regiones Aéreas. Buenos Aires, Argentina. (información digital proporcionada por el Servicio Meteorológico Nacional, s/fecha)

\section{PÁGINAS WEB CONSULTADAS:}

Servicio Meteorológico Nacional S.M.N: (www.smn.gov.ar)

Instituto Nacional de Tecnología Agropecuaria INTA: (www.inta.gov.ar)

Oficina de Riesgos Agropecuarios: (www.ora.gov.ar)

Publicado en formato digital: Prof. María de los Ángeles Martínez Jiménez y Prof. Patricia Perla Snaider. LA OCURRENCIA DE HELADAS Y SU INFLUENCIA EN LAS FASES DE LOS CULTIVOS EN LA PROVINCIA DEL CHACO ENTRE 1951 Y 2000. Revista Geográfica Digital. IGUNNE. Facultad de Humanidades. UNNE. Año 11. No 21. Enero - Junio 2014. ISSN 1668-5180. Resistencia, Chaco. 